J. Linguistics 57 (2021), 83-121. ㄷ The Author(s) 2020.

Published by Cambridge University Press. This is an Open Access article, distributed under the terms of the Creative Commons Attribution licence (http://creativecommons.org/licenses/by/4.0/), which permits unrestricted re-use, distribution, and reproduction in any medium, provided the original work is properly cited.

doi:10.1017/S0022226720000134

\title{
Nuclear prominence in ellipsis: Evidence from aggressively non-D-linked phrases ${ }^{1}$
}

\author{
GÜLİZ GÜNEŞ『 \\ Leiden University \& University of Tübingen \\ ANIKÓ LIPTÁK ${ }^{\oplus}$ \\ Leiden University
}

(Received 30 September 2019; revised 9 March 2020)

This paper investigates the reason why aggressively non-D-linked items such as wh-the-hell (WTH) are allowed in swiping, but not in sluicing. Investigating the potential syntactic, semantic and prosodic licensors of WTH in sluicing and swiping in the British English variety, we conclude that syntactic or semantic constraints cannot be the source of the difference. Instead, we propose a novel prosodic account in which the WTH must satisfy the prosodic licensing condition that it cannot bear nuclear accent. We show that this is satisfied in swiping, but not in sluicing contexts. On the basis of the novel findings of an acceptability rating study of swiping, which reveal that both 'given' and 'new' prepositions are equally acceptable for British English speakers, we argue that the preposition is accentuated in this elliptical construction because it is structurally the deepest element. The licensing condition on WTHs in sluicing and swiping is therefore not mediated directly by the conditions on ellipsis, but by the particular prosodic distribution that a WTH happens to have in sluicing and swiping. We extend the account to similar constructions in Dutch.

KEYWORDS: aggressively non-D-linked phrases, British English, deaccentuation, Dutch, ellipsis, nuclear accent, prosody, sluicing, swiping

\section{INTRODUCTION}

SLUICING is ellipsis of a Tense Phrase (TP) to the exclusion of a single (in some cases multiple) wh-constituent (Ross 1969), illustrated in (1a) below, in which

[1] We would like to thank the editors and two anonymous referees of the Journal of Linguistics, three reviewers of Natural Language \& Linguistic Theory, as well as the audience of the Ellipsis across Borders Conference (Sarajevo 2016), and Jeroen van Craenenbroeck, Marcel den Dikken, Lynn Frazier and James Griffiths for discussions and suggestions for the material in this paper. We also gratefully acknowledge the help of Victoria Nyst, our British English and Dutch consultants and Rianne van Lieburg, who has helped us design, run and analyse the results of the experiment in Section 2.2. This research is funded by NWO (Dutch Organisation for Scientific Research). In this paper, the Leipzig Glossing Rules conventions are supplemented by the following abbreviations: $\mathrm{AFF}=$ affirmative marker; $\mathrm{PRT}=$ verbal particle. 
the elided part is set with strikethrough. SWIPING is a variant of sluicing with a prepositional question phrase remnant, in which a $w h$-item is followed, rather than preceded, by a preposition (1b) (Merchant 2002). ${ }^{2}$ The $w h+$ preposition order attested in swiping is only allowed under ellipsis and cannot be found in nonelliptical clauses (1c).

(1) (a) John fixed the car, but I don't know with what

[TP John fixed the car]. (sluicing)

(b) John fixed the car, but I don't know what with

[TP John fixed the ear]. (swiping)

(c) *John fixed the car, but I don't know what with

John fixed the car. (non-elliptical $w h+$ preposition)

AGGRESSIVELY NON-D-LINKED ITEMS are phrases, such as the hell, the heck, on earth, in the world, the Dickens, the fuck, in god's name, the fucking fuck, in heaven, etc., that cannot involve overt markers of discourse linking, such as which (as in *which the hell). These items are compatible only with wh-phrases that do not involve discourse linking, such as what (as in what the hell) (Pesetsky 1987). In this paper, we investigate the reason why aggressively non-D-linked items (e.g. the hell; hereafter THs) that follow a wh-item (e.g. what the hell; hereafter WTHs) are allowed in swiping, but not in sluicing, a puzzle that has been noted by many before us (Merchant 2001, Den Dikken \& Giannakidou 2002, Sprouse 2006, Hartman \& Ai 2009, van Craenenbroeck 2010b).

(2) The puzzle: WTH is allowed in swiping but not in sluicing

(a) John fixed the car, but I don't know what the hell with. (swiping)

(b) *John fixed the car, but I don't know with what the hell. (sluicing)

The main question that is addressed in this paper is why (2) holds, i.e. why WTHs are allowed in swiping, but not in sluicing, and whether this difference follows from differences between sluicing and swiping as established in previous works. The question that needs to be addressed is then what the licensing conditions on WTHs are, and if these conditions by any chance interact with the particular syntactic, semantic or prosodic properties of elliptical constructions such as sluicing and swiping.

In this paper we give a characterisation of WTH expressions and show that their restrictedness to swiping has a prosodic explanation, confining all our claims to the British English variety. First, we show that the puzzle does not gain an explanation if one considers the syntactic and semantic properties of sluicing and swiping (Section 2). As part of this section, we present the results of an online sentence acceptability study with British English consultants showing that the acceptability of swiping does not depend on the information structural status of the preposition in the swipe, despite claims to the contrary in some earlier works

[2] The term 'swiping' is an acronym derived from: sluiced $\underline{w} h$-word inversion with prepositions in Northern Germanic (Merchant 2002). 
on the topic. This finding also allows us to choose the right syntactic account of swiping and set the scene for our account of the accentuation of swiping.

In the second part of the paper, we argue that the explanation is prosodic in nature. We first review the pioneering account of Sprouse (2006) of the puzzle briefly in Section 3, pointing out its major shortcomings. In Section 4 we propose a prosodic account that explains the puzzle as the interaction of two factors: accentuation of the elliptical remnants of sluicing and swiping and the requirement that WTH expressions cannot carry nuclear accent. We derive the accentuation profile of sluicing and swiping via the nuclear accent placement algorithm that we advance for elliptical structures, according to which nuclear accent is assigned to the structurally deepest element outside the elliptical domain. In Section 5, we extend the scope of our investigation to Dutch, a language where epiphets in $w h$-constituents are similarly constrained in their prosody.

\section{Syntactic AND SEMANTIC CONSIDERATIONS DO NOT EXPLAin THE PUZZLE}

In this section, we consider the syntactic and semantic properties of sluicing, swiping and WTH expressions in the search of an explanation for the puzzle illustrated in (2). In Section 2.1, we first describe sluicing and swiping by listing the most important properties of these elliptical constructions, together with a brief characterisation of WTH phrases. We note that there has been a disagreement in the literature regarding the 'given' vs. 'new' status of the stranded preposition in swiping, which may be (at least) partly due to differences in the distinct varieties of English (American vs. British) studied in previous research. Concerning ourselves with one variety only, the British English variety, we then adduce experimental evidence for the claim that the information structural status of the preposition in swiping can be either given or new (Section 2.2). In the light of this, we adopt the account of van Craenenbroeck (2010a) for the syntax of swiping and the standard view of sluicing as TP-ellipsis (Merchant 2001) (Section 2.3). In view of the syntactic structures of swiping and sluicing, in Section 2.4 we argue that syntax cannot explain why swiping is well-formed with WTH, but sluicing is not, and neither can semantic considerations predict this discrepancy.

\subsection{Properties of sluicing, swiping and wh-the-hell items}

Sluicing is deletion of a $w h$-interrogative clause to the exclusion of the question constituent, which is derived by movement of the wh-phrase to the Spec,CP position and TP-ellipsis (e.g. Ross 1969, Merchant 2001). Sluicing can occur in matrix and embedded contexts and with any kind of wh-phrase (see Vicente 2018 for details and an overview of the existing literature). Thus, PP remnants as well as DP remnants are acceptable, and the latter can also strand their selecting prepositions (when the preposition has an antecedent, Chung 2006). 
(3) (a) John fixed the car, but I don't know with what [Tе John fixed the car $t_{\mathrm{PP}^{-}}$].

(b) John fixed the car with something, but I don't know what

[TР Jøhn fixed the car with $t_{\text {ĐP }}$.

Swiping is a subtype of sluicing with a prepositional phrase as remnant, in which the preposition follows the wh-constituent (recall footnote 2 above). Swiping differs from sluicing in some crucial properties. We review these below, restricting our attention to swiping with a single remnant only (see Richards 2001, Merchant 2002 and van Craenenbroeck 2010a for multiple remnants).

Two of the uncontested properties of swiping are that swiping only occurs in sluicing (the wh-complement of a preposition can only precede it in TP-ellipsis contexts) and that the preposition in swiping bears accent. The latter is illustrated with reference to (4a) and (4b), where accent is signaled by capitals. While in sluicing with a prepositional remnant, it is the wh-expression that is accented, in swiping accent must fall on the preposition. This observation is crucial for the rest of this paper.

(4) (a) Ben was talking, but I don't know \{to WHOM/*TO whom \}.

(b) Ben was talking, but I don't know $\{*$ WHO to/who TO $\}$.

There also appears to be a restriction on the size of $w h$-constituents that can occur in swiping. With a few exceptions, swiping is claimed to occur with 'minimal' (i.e. head-type) $w h$-items in Merchant (2002: 296-297), and van Craenenbroeck (2010a), as seen in the contrast between (4a) and (4b). Hartman \& Ai (2009) and Radford \& Iwasaki (2015) on the other hand state that swiping is well-formed with complex $w h$-phrases as well.

(5) (a) Lois was talking, but I don't know who to.

(b) *Lois was talking, but I don't know which person to.

The size of the allowed wh-constituent might be due to systematic variation between American and British English. Whichever way is the correct way of stating this property, the data we are concerned with, namely swiping with whthe-hell expressions, can only contain minimal wh-expressions (so the issue has no consequence for the discussion to follow). This is due to the independent restriction that aggressively non-D-linked $w h$-elements are only well-formed with minimal $w h$-items. In other words, the hell and its ilk is only allowed after simplex wh-operators, as established by Merchant (2002) (with reference to Pesetsky 1987). Our British English consultants share this judgement.

(6) (a) John was talking, but I don't know who the hell to.

(b) *John was talking, but I don't know what girl the hell to.

For this reason, we follow Merchant (2002) in saying that the hell is a marker that attaches to $w h$-heads and forms a single (complex) head with them (see also Den Dikken \& Giannakidou 2002 for the same claim). The wh-item and the hell 
form a single head, and such a single head is predicted to be well-formed in swiping. ${ }^{3}$

Another property of swiping concerns the type and the information structural status of the prepositional phrases that are acceptable in swiping. Rosen (1976) was the first to state that swiping is well-formed with prepositional phrases that are non-obligatory in their clause, i.e. they can be implicit arguments or adjuncts, as seen in $(7 \mathrm{a}, \mathrm{b})$ below. However, as seen in $(7 \mathrm{c}, \mathrm{d})$, PPs that cannot be omitted in the antecedent, such as predicative PPs or PPs forming part of an idiom, are ill-formed in swiping.

(7) (a) Shirley went to Gristleburg, but nobody knows who with.

(Rosen 1976: ex. (13))

(b) The neighbors have been complaining. Guess what about.

(c) We were with somebody. *I forget who with.

(Rosen 1976: ex. (4))

(Rosen 1976: ex. (9))

(d) Smersh intends to do away with someone. *Find out who with.

(Rosen 1976: ex. (19))

While no explanation has been offered to date for the ill-formedness of predicative and idiomatic PPs, quite some ink has been spilled on the information structural status of those PPs that are acceptable remnants of a swiping clause (i.e. PPs that are implicit arguments and adjuncts). Whether the preposition in swiping can or cannot have an overt antecedent in these cases, in other words, whether its content can be GIVEN or NEW has been subject to some contention. We use the term 'given' preposition here with respect to a preposition occurring in the antecedent clause as is standardly done, regardless of the actual position of the correlate PP inside or outside the VP. We consider a preposition NEW if it is not present in the antecedent clause. See Merchant (2002) for an account that capitalizes on this distinction to derive the observation that adjunct PPs can have overt antecedents in swiping. According to Rosen (1976), prepositional phrases that do not have an overt antecedent - i.e. PPs that are NEW in the swiping clause when it comes to information status - are better than those that are GIVEN. In her judgement, $(8 \mathrm{~b})$ is better than $(8 \mathrm{a})$, but both are acceptable.

[3] Independent proof of head-adjunction of the hell is provided by the fact that the hell can occur in complex $w h$-phrases as well, but only following the $w h$-head and in no other position. The example in (ia) below is from the literature, (ib) has been provided as acceptable by two consultants, contra the observation in Pesetsky (1987).

(i) (a) How $\{$ the hell $\}$ potent $\{*$ the hell $\}$ do you think this is? !?

(Merchant 2002: fn. 9 ex. (ib))

(b) Which $\{$ ?the hell $\}$ girl $\{*$ the hell $\}$ did he meet?

(two British English consultants)

See also example (53) for morphological evidence for head-adjunction of the equivalent of the hell in Hungarian WTH phrases. 
(8) (a) Howard shares the apartment with someone, but I have no idea who with.

(b) Howard shares the apartment, but I have no idea who with.

Merchant (2002) \& van Craenenbroeck (2010a) also consider both versions acceptable and thus allow the preposition in swiping to be given, but Sprouse (2006) and Hartman \& Ai (2009) state that no preposition in swiping can have an antecedent, ruling out cases such as (8a) and stating that the preposition in swiping must always be new. This issue is highly relevant for us as it directly informs us regarding what information structural status - and in line with it, what kind of prosodic realisation and syntactic position - the preposition has in swiping. The contradictory findings in the literature when it comes to the givenness/newness of the prepositions may potentially be due to a systematic difference between American and British English. To steer clear of such potential intervarietal differences between distinct grammatical systems in this respect, we decided to investigate this aspect of swiping experimentally, in a systematic way, and in only one variety, namely British English. This is also the variety that the rest of paper will make claims about. We leave the question if (and if so, how) American English differs from British English for future research.

Before turning to the experiment and its findings in Section 2.2 below, we close this section by mentioning another aspect of information structure on swiping, namely the CONTRASTIVITY of the preposition. Radford \& Iwasaki (2015) claim that contrastivity has no effect on the acceptability of swiping: swiping is equally allowed with a non-contrastive and a contrastive preposition, where contrast is defined with respect to a preposition in the antecedent, as seen in (9):

(9) A gift was given: we know who BY, but we don't know who TO.

Hartman \& Ai (2009) claim that the preposition cannot be contrastive. Since all four of our British English consultants accept examples like (9), we follow Radford \& Iwasaki (2015) in our characterisation of swiping, and claim that the preposition in swiping can be contrastively focused in the language variety we are interested in.

\subsection{The givenness/newness of swiping remnants: An experimental study of British English}

We have conducted a web-based acceptability judgement experiment to address the question whether the givenness/newness of the preposition impacts the acceptability of swiping. Experimental items were constructed across two factors: ellipsis (swiping vs. non-elliptical structure with P-stranding) and the information status of the preposition (given vs. new). If givenness impacts the acceptability of swiping, we expect that acceptability ratings should drop with respect to nongiven prepositions in swiping (in the ellipsis condition). As a similar effect has not been reported for non-elliptical sentences in the literature (as far as we know), 
we do not expect such a drop in non-elliptical sentences. For this reason, we have used non-elliptical equivalents of the swiping examples (with P-stranding) as controls in the experiment in a full factorial $2 \times 2$ design, where the factors were the presence of ellipsis and givenness of the preposition. We created four conditions, illustrated in Table 1. There were the following seven lexicalisations for each condition: dance with, swim with, talk to, laugh at, look at, listen to, complain to, all containing monosyllabic prepositions. In each case, the optional prepositional phrase was adjacent to the verb (which is predicted to be possible in swiping - recall Rosen's (1976) generalisation illustrated by examples (7a, b) above). ${ }^{4}$

\begin{tabular}{lcc}
\hline Sentence type & New preposition & Given preposition \\
\hline Swiping (ellipsis) & $\begin{array}{c}\text { Condition 1 } \\
\text { John was talking, } \\
\text { but I don't know who to. }\end{array}$ & $\begin{array}{c}\text { Condition 2 } \\
\text { John was talking to someone, } \\
\text { but I don't know who to. }\end{array}$ \\
\hline $\begin{array}{c}\text { Condition 3 } \\
\text { Non-ellipsis }\end{array}$ & $\begin{array}{c}\text { John was talking, but I don't know } \\
\text { who he was talking to. }\end{array}$ & $\begin{array}{c}\text { John was talking to someone, but I } \\
\text { don't know who he was talking to. }\end{array}$ \\
\hline
\end{tabular}

Table 1

The $2 \times 2$ design of the experimental item sets.

As the experiment was designed to test the (null) hypothesis that there is no difference between given and new prepositions in swiping - thus challenging earlier published statements - we decided to test the difference between given and new prepositions in three distinct ways. The experiment is hence composed of three tasks.

The first was a forced choice task (Task 1), in which participants were presented with two sentences and they had to pick the most acceptable sentence. Comparisons were made between Conditions 1 and 2, and similarly, between Conditions 3 and 4 (refer to Table 1). The order of the sentences varied (in some cases the first sentence was one with a new preposition, in others, the one with a given preposition was first). This task included four experimental items and six fillers. It was preceded by four practice items containing sluicing and predicate-ellipsis, whose purpose was to introduce the contexts needed for judging the experimental items. A sample of the practice set-up with a context is given below:

[4] We did not investigate data in which a PP is obligatory in the antecedent, such as obligatory arguments, predicative PPs (as in (7c)) and PPs in an idiom chunk (as in (7d)), because we were only interested on the effect of givenness of prepositions that can appear in swiping. 
(10) [Context: The family car had broken down, and no-one could fix it because no-one had the necessary tools. One day you notice that the car is working again, and wonder who fixed it, but more than anything you wonder how they managed it without the tools. Your brother knows that Sue fixed the car so he says (pick the most acceptable).]

(a) Sue's fixed the car, but I don't know with what.

(b) Sue's fixed the car, but I don't know with what fixed.

The participants were instructed to think of similar contexts when judging the experimental items. All items were randomised.

The second task was a five-point Likert scale acceptability judgement task (Task 2), in which the participants were asked to grade how acceptable the items were $(1=$ completely unnatural, coloured red; $5=$ completely natural, coloured green). Grades 2, 3 and 4 were not labelled but were coloured orange, yellow and blue, respectively. In addition to the four experimental items, the task also contained four practice items (with contexts specified) and six fillers. All items were randomised.

The last task was a yes/no task (Task 3), in which participants were presented with individual sentences and asked to answer the question 'Is this sentence good?' by clicking either 'yes' or 'no'. In case of doubt, they were instructed to click 'yes' if the sentence was, in their judgment, closer to being good, and 'no' if it is closer to being bad. In addition to the four experimental items, the task also contained four practice items (with contexts specified) and six fillers. All items were randomised.

We distributed the test items with different lexicalisations among two participant lists, in order to keep the questionnaire at a manageable length. Except for the forced choice task, none of the four conditions that are tested shared the same lexicalisation. Other than the lexicalisations, the two surveys were completely identical in every respect. In total, participants judged 42 sentences in both lists.

Materials were presented and recorded using the Qualtrics platform, and distributed via the online data collection platform Prolific. A total of 108 participants were recruited online via Prolific, 52 participants completed the first list and 56 participants completed the second list. Participants received a compensation of $£ 1.70$ (first list) and $£ 1.36$ (second list). All participants had British nationality, were native speakers of British English, raised monolingual with English as their first language. They were aged between 20 years and 50 years, and all had a university degree.

\subsubsection{Results of the experiment}

In the forced choice task (Task 1), we tested whether participants find swiping more acceptable with new prepositions rather than with given prepositions. Table 2(a) shows the amount of preference for each test condition. 


\begin{tabular}{lcc}
\hline Sentence type & New preposition & Given preposition \\
\hline (a) Swiping & $52(48.1 \%)$ & $56(51.9 \%)$ \\
\hline (b) Non-ellipsis & $\begin{array}{c}75(69.4 \%) \\
\text { (e.g. John was talking, but I don't } \\
\text { know who he was talking to.) }\end{array}$ & $\begin{array}{c}\text { (e.g. John was talking to someone but I } \\
\text { don't know who he was talking to.) }\end{array}$ \\
\hline
\end{tabular}

Table 2

(a) Number (and percentage) of answers selecting a condition as better than other.

(b) Number (and percentage) of answers selecting a condition as better than other.

The null hypothesis is that the participants choose between given and new prepositions in the swipe at chance level, which is 50\%. To test whether participants either preferred a new preposition or a given preposition, a binomial test was run using the binom.test() function in R. In the swipe condition, given and new preposition were chosen equally often $(p=.773)$. This shows that there is no significant difference between the acceptability of swiping with given and new prepositions.

Indication that the participants were sensitive to the task, and did not judge all examples randomly comes from two observations. On the one hand, practice items that compared fully acceptable and fully unacceptable elliptical examples were judged according to expectation, as shown by the following pair of examples:
(a) Lisa will come, but I don't know when.
(count: 108, 100\%)
(b) Lisa will come, but I don't know when will. (count: 0, 0\%)

Second, in the non-elliptical conditions where we tested the effect of the information status of the preposition on non-elliptical equivalents of swiping, participants picked the sentence with a new preposition significantly more often than at chance level ( $p=.000065)$, as the raw numbers in Table 2(b) also illustrate at a glance (see footnote 5 on this).

In the Likert scale task (Task 2), we asked the participants to judge each experimental item on a scale from 1 (completely unnatural) to 5 (completely natural). The mean scores and the standard deviations are given in Table 3.

\begin{tabular}{lcc}
\hline Sentence type & New preposition & Given preposition \\
\hline Swiping & $4.29( \pm 0.821)$ & $4.05( \pm 0.961)$ \\
\hline Non-ellipsis & $4.37( \pm 0.792)$ & $4.35( \pm 0.765)$ \\
\hline
\end{tabular}

Table 3

Mean acceptability judgement $( \pm \mathrm{SD})$ per condition.

Using the lmer() function from the lme4 package in R (Bates et al. 2013), a linear mixed regression model was run to test for differences between means. Condition was taken as a fixed effect. A random slope was included for each 
participant. To obtain pairwise comparisons, a post-hoc test with Bonferroni correction was performed using the emmeans() function (Lenth 2018). In the swipe condition, no significant difference in acceptability was found between sentences with a new preposition and sentences with a given preposition ( $p$ $=.0932$ ). This result confirms the result of Task 1 for swiping. Similarly, no difference was found in the non-elliptical condition $(p=1.00)$, which is in line with the expectation that non-elliptical sentences are acceptable with both given and new prepositions.

In the yes/no task (Task 3), participants had to decide whether or not a sentence was acceptable by choosing between 'yes' or 'no'. The distribution of these answers is presented in Table 4.

\begin{tabular}{lcc}
\hline Sentence type & New preposition & Given preposition \\
\hline \multirow{2}{*}{ Swiping } & Yes: 106 & Yes: 95 \\
& No: 2 & No: 13 \\
\hline \multirow{2}{*}{ Non-ellipsis } & Yes: 104 & Yes: 106 \\
& No: 4 & No: 2 \\
\hline
\end{tabular}

Table 4

Raw numbers of 'yes' and 'no' answers per condition.

With the help of the pairwiseNominalIndependence() function of the rcompanion package (Mangiafico 2018), pair-wise comparisons were established with Bonferroni correction, conducting chi-square tests. In the swipe condition, sentences with a given preposition were accepted significantly less often than sentences with a new preposition $(p=.0446)$. Note, however, that under the swiping condition, $87.96 \%$ of the participants judged the given preposition as good. In the non-elliptical condition, no significant difference was found $(p=1.00)$.

The results of the three tasks indicate that there is no statistically significant difference between the acceptability of given and new prepositions in swiping according to Task 1 and Task 2, and there is a marginal difference between them according to Task 3 . Since the results of Task 3 approach non-significance, we take this test to point in the same direction as the other two tests: we claim that the givenness of the preposition does not play a role in the acceptability of swiping for the British English speakers we consulted.

The same can be said about the givenness of the preposition in non-elliptical contexts, according to the evidence of Task 2 and Task 3. We leave the contradictory results of Task 1 for the non-elliptical control conditions for further research, as it is tangential to our present purposes. ${ }^{5}$

[5] One possibility is that the contradictory results are due to the effect of wordiness in nonelliptical sentences, which only plays a role when consultants are asked to compare a more 


\subsection{The syntactic configuration of sluicing and swiping}

Having established the properties of sluicing and swiping in the previous two subsections, now we are in position to set our assumptions about the syntactic configuration of swiping and sluicing.

Concerning the syntax of swiping in British English, we assume that swiping involves two leftward movement steps: a movement of the PP out of the ellipsis site, followed by a movement, which strands the preposition. We adopt the proposal by Richards (2001), who dissociates these movement steps from focusing, and concerning the details, we specifically follow van Craenenbroeck's (2010a) split CP-variant of the Richards-style analysis, illustrated in (12), in which both steps of movement target a high left peripheral position, labelled $\mathrm{CP}_{1}$ and $\mathrm{CP}_{2}$ below.

The syntactic configuration of swiping (van Craenenbroeck 2010a)

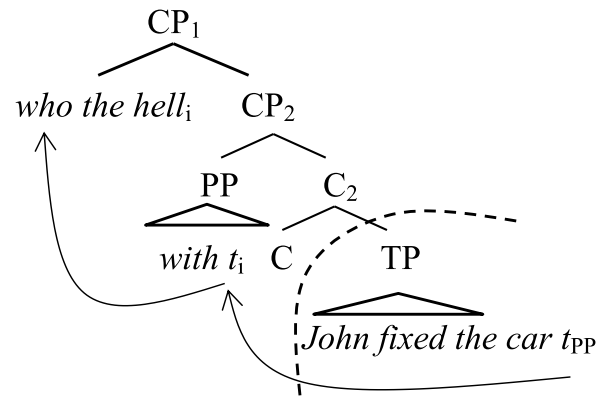

Importantly, given the results of our five-point Likert scale acceptability judgement task (Task 2), we take it that the movement of the PP out of the ellipsis site does not take place to a specific focus position, triggered by an (information or contrastive) focus feature. Instead (again following van Craenenbroeck 2010a), we term the lower CP position as an operator position and the higher one a clausetyping position.

In other words, we reject proposals in which the derivation of swiping involves a crucial movement step that manoeuvres the preposition into a focus position, to account for the fact that the preposition is always new and thus receives information focus - and focal accent as a result. We do this as we have observed

wordy and a less wordy sentence to each other, as a response to the instruction that they choose the most acceptable one of the two. In the case of given prepositions (Condition 4), the initial clause is longer; and there is one more word repeated in the second clause (the preposition) than in the new condition (Condition 3), where the initial clause is shorter and there are fewer words repeated in the second clause. Possibly, this is because, when they are forced to make a comparison between two acceptable sentences, speakers consider not only the wellformedness of the sentence but also its style (sentence length, repetition of material, etc.). When two conditions are not minimally compared but judged independently, such considerations do not apply (compare the results of Task 3 for Conditions 3 and 4 in Table 4). Why this effect of wordiness is only detectable in non-elliptical sentences remains a mystery. 
in Section 2.2 that givenness/newness of the preposition has no effect on the acceptability rates among our British English consultants. Prepositions in swiping CAN but need not be given and CAN but need not be contrastive with respect to a preceding PP. On the basis of these observations, we conclude that the syntactic distribution (and the accent) of the P in swiping is NOT mediated by information structure. We thus claim that the position of the preposition is not due to focus movement of the PP (Kim 1997, Hartman \& Ai 2009), or focus movement of the $\mathrm{P}$ alone (Radford \& Iwasaki 2015).

With the above syntactic derivation, we capture not only that swiping coexists with the possibility of P-stranding across languages (Merchant 2002, van Craenenbroeck 2010a, Radford \& Iwasaki 2015), but also that the wh-phrase in swiping can be at a long distance from its preposition, crossing a finite clause boundary (van Craenenbroeck 2010a, Radford \& Iwasaki 2015), as illustrated in (13):

(13) A: Mary thinks her elderly father has eloped.

B: Is she crazy? Who the hell does she think with?

Concerning the question why swiping (and thus swiping with WTH as well) only exists under ellipsis, we follow van Craenenbroeck (2010a) in taking this to be an instance of ellipsis repair: PP movement to $\mathrm{CP}_{2}$ should bar further movement of a subconstituent to a higher position in non-elliptical clauses due to non-uniform chain formation; ellipsis, on the other hand, repairs this violation by eliminating illicit traces in TP.

As for sluicing, we adopt the standard analysis whereby sluicing involves movement of the wh-phrase to the Spec,CP position and TP-ellipsis (e.g. Ross 1969, Merchant 2001), as illustrated in (14). ${ }^{6}$

The syntactic configuration of sluicing

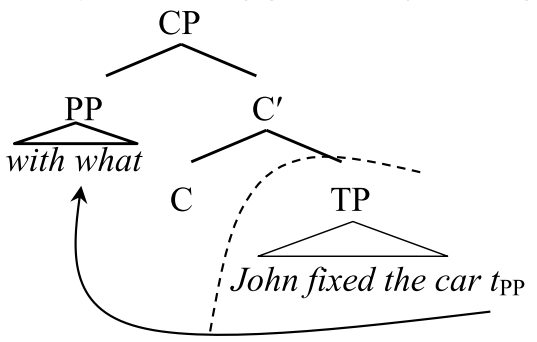

[6] In van Craenenbroeck (2010a), which uses a split CP structure, the position of the wh-phrase corresponds to the specifier of the higher $\mathrm{CP}$ projection, the projection of the clause typing $\mathrm{C}$ head, when the fronted constituent contains a simplex $w h$-item. While nothing hinges on the choice between the split and the unsplit CP analysis, we adopt the unsplit CP analysis for sluicing, due to the fact that the key work to be discussed in the next section (Den Dikken \& Giannakidou 2002) adopts this kind of analysis as well. 


\subsection{Back to the puzzle: Can syntax or semantics provide an explanation?}

We now turn to the following question: Can the unavailability of WTH in British English sluicing examples like (2b) above be explained with reference to syntax or semantics? As it has been noted in earlier works that WTH has syntactic and semantic licensing requirements, we review these requirements one by one to see whether they are satisfied under sluicing. The outcome of this discussion will be that they are satisfied; therefore, these aspects of syntax and semantics do not provide an explanation for our puzzle.

The first observation concerning the syntactic licensing of WTH is that these phrases cannot appear in situ in English, as seen in (15a), but are perfectly wellformed when moved to Spec,CP (Den Dikken \& Giannakidou 2002, Huang \& Ochi 2004):

(a) *Who has seen who the hell?

(b) Who the hell has John seen?

Clearly, this licensing requirement is satisfied in the environment of sluicing (Sprouse 2006): as Merchant (2001) has argued, sluicing remnants always correspond to $w h$-phrases moved to $\mathrm{Spec}, \mathrm{CP}$, as (16) illustrates:

(16) *John fixed the car, but I don't know [сР with what the hell $\left.\mathrm{fTP}_{\mathrm{i}} t_{\mathrm{i}} \mathrm{f}\right]$

Furthermore, as Den Dikken \& Giannakidou (2002) have shown, WTH phrases are polarity items that are inadmissible in veridical contexts. This means that they must occur in non-veridical environments (such as in the scope of a negative quantifier or only, being in a conditional). When it comes to their occurrence in matrix and embedded wh-clauses, antiveridicality requires that they should be licensed as polarity items. Licensing can be done by the matrix question operator $\mathrm{Q}$ in its c-command domain, as in (17a), interrogative-selecting verbs such as ask or wonder, as in (17b), or negated veridical verbs like know, tell and matter (but see Hoeksema \& Napoli 2008 for further refinements concerning the set of predicates), seen in $(17 \mathrm{c}, \mathrm{d})$.

(17) (a) Who the hell has John seen? (WTH licensed by Q)

(b) I wonder who the hell John has seen. (WTH licensed by wonder)

(c) I don't know what the hell Mary is reading.

(WTH licensed by negated PREDICATE)

(d) It doesn't matter who the hell John will kiss.

(WTH licensed by negated PREDICATE)

Den Dikken \& Giannakidou (2002) claim that in these contexts, WTH phrases are properly licensed as polarity items.

Exactly the same syntactic configurations, however, do not give rise to wellformed WTH phrases if the clause in which they occur undergoes sluicing (TPellipsis): 
(18) (a) A: John has seen someone.

B: Who?/*Who the hell?

(b) John has seen someone. I wonder who/*who the hell.

(c) I can see Mary is reading something, but I don't know what/*what the hell.

(d) John will kiss anyone after the first date, it doesn't matter who/*who the hell.

Clearly, the polarity item licensors are present in these elided clauses as well, as the syntactic configuration and the lexical content of the sentences are the same: (18a) contains a Q operator c-commanding the WTH; (18b) contains an interrogative selecting predicate (wonder), $(18 \mathrm{c}, \mathrm{d})$ contain the negated veridical predicate know and matter. This shows that the unacceptability of WTH in sluicing is not due to the lack of polarity item licensing as specified above.

Why would WTHs be unavailable in sluicing, then? Even though polarity item licensing is satisfied, a potential semantic problem might arise in the way the WTHs are anchored to the previous context - this is in fact the explanation that Den Dikken \& Giannakidou (2002) offer to explain the puzzle. According to them, the unacceptability of WTHs in $(18 \mathrm{a}-\mathrm{d})$ is due to the specific discourse context that sluicing requires, which disallows the use of WTHs. In sluicing, there is a specific indefinite with an existential presupposition, which serves as a correlate to the $w h$-remnant phrase. In their analysis, aggressively non-D-linked WTHs are a type of DEPENDENT INDEFINITES, meaning that they do not assert existence and cannot be anaphoric to a previously introduced discourse referent. Since in sluicing the $w h$-remnant must be anaphoric to an indefinite, WTHs fail to occur in sluicing as they cannot be linked to discourse familiar entities.

The problem with this explanation is that WTH-phrases do not rule out discourse antecedents in the exact same discourse environment when they are not followed by ellipsis. It is perfectly straightforward to construe questions with WTH phrases using episodic tense as genuine information questions that seek information about the identity of a referent (as Den Dikken \& Giannakidou 2002 themselves note elsewhere in their article). Indeed, our consultants considered the full clause equivalents of $(18 \mathrm{a}-\mathrm{d})$ well-formed with this reading - see the data in (19). ${ }^{7}$

[7] Notice that the data in (19a-d) have been reported to be well-formed only if the area that follows WTH is NOT deaccented and the sentence-final verb in each case receives an accent. When this area is deaccented, the structures are considered unacceptable. See (39) for such cases. 
(19) (a) A: John has seen someone.

B: Who the hell has he seen?

(b) John has seen someone. I wonder who the hell he has seen.

(c) I can see Mary is reading something, but I don't know what the hell she is reading.

(d) John will kiss anyone after the first date, it doesn't matter who the hell they are.

In these cases, too, there is a presuppositional indefinite which serves as a correlate to the WTH expression and the sentences are well-formed. This shows that the unavailability of WTHs in sluicing cannot be due to the specific discourse context sluicing requires in these examples.

It is important to stress that in the examples discussed in this section, we are providing cases of WTH that have a genuine information seeking reading. As we show above in (19), such WTH constructions are well-formed with episodic tense in them and are compatible with an existential presupposition in an antecedent clause. These WTHs therefore should be discourse-licensed in sluicing. We are not making claims about the acceptability and the well-formedness of WTH constructions with a negative rhetorical meaning, such as Who the hell would do such a thing?, which constitute another type and use of WTH. WTHs with negative rhetorical reading have distinct semantic and discourse properties: as Den Dikken \& Giannakidou (2002) show, negative rhetorical readings of WTHs must be licensed by a modal and expect a negative answer, which is incompatible with an existential presupposition. The way we differ from Den Dikken \& Giannakidou (2002), then, is that we make a distinction between genuine information seeking WTHs and negative rhetorical WTHs when it comes to availability in sluicing, and we claim that genuine information seeking WTHs are properly discourse-licensed in sluicing as they are compatible with an existential presupposition of a correlate.

That WTHs and presuppositionality are not incompatible is clear from the observation that strongly presuppositional it-cleft questions also allow for the use of WTH, with information-seeking content, as the following examples illustrate.

(20) (a) I can see you can't walk straight. What the hell was it that you have been drinking?

(b) I see your sister is crying. What the hell was it that you did to her?

Last but not least, there are languages, such as Hungarian, in which WTH expressions are well-formed in elliptical and non-elliptical sentences alike, see the case of sluicing with a WTH expression in (21).

(21) Jani megjavította a kocsit, de nem tudom, Jani PRT.fixed the car.ACC but not know.1SG

mi a bánattal. (Hungarian)

what the sorrow.INST

Lit.: 'Jani fixed the car, but I don't know with what the hell.' 
This shows that the specific discourse context required by sluicing can support WTH phrases, further reinforcing our claim that the unavailability of WTHs in sluicing in English cannot be due to discourse semantic factors.

\section{CAN PROSODY PROVIDE AN EXPLANATION?}

In this section, we turn to the question whether the relevant licensing condition could be prosodic and review the proposal in Sprouse (2006) to this effect. Our conclusion will be that although a prosodic approach may indeed be required to account for the data, Sprouse's approach is inadequate. Before discussing Sprouse's prosodic account, we present the core prosodic properties of WTHs in British English in the context of swiping.

\subsection{Main prosodic properties of swiping with and without the hell (TH) in British English}

We have established the prosodic properties of swiping on the basis of the existing literature and consultations/recording sessions with four British English speakers (three female and one male). The speakers were individually consulted in speech about the acceptability of sluicing and swiping sentences with and without WTHs as well as the non-elliptical equivalents of such sentences ( 84 sentences in total), and were recorded when reading out the acceptable examples, which were then inspected in PRAAT (Boersma \& Weenink 2011). All British English examples illustrated with a pitch track below come from this pool of sentences and are given as a representative of the prosodic profile of the structures under discussion.

As for the accentual properties of the preposition in swiping, it has been reported in the literature that the preposition in swiping (with or without $\mathrm{TH}$ ) bears a high pitch accent (i.e. a pitch peak associated with a stressed syllable, $\mathrm{H}^{*}$ ). When asked about the prominence on the preposition in swiping, our speakers commented that the preposition is perceived as the most prominent unit of the elliptical clause. The nature of this accent is SENTENCE-LEVEL NUCLEAR PITCH ACCENT (NA), which is the accent that is perceived as the most prominent accent in an intonational phrase.

Prosodically, among the phonological phrases within an intonational phrase, an NA in British English (but also German and Dutch) is the highest pitch accent $\left(\mathrm{H}^{*}\right)$ within the rightmost phonological phrase of that intonational phrase (see e.g. Truckenbrodt 1995, 1999, 2006; Ladd 1996; Féry 2011). Although the prosodic description of an NA states that the linearly rightmost accent is the NA of that sentence, this does not necessarily mean that an NA always falls onto the rightmost syntactic constituent/word of a clause. An NA may be followed by other items that do not bear phonological phrase-level pitch accent.

As for the location of an NA, we observed that not only prepositions that are new, but also prepositions that have a correlate in the antecedent clause can be the locus of the NA of that clause. Figure 1 illustrates a case in which a new 
preposition (in this case about) bears the NA within the intonational phrase that corresponds to the elliptical clause (i.e. within the string but I don't know who the hell about) - the intonational phrase boundary tones are marked with a \% sign next to the tone of that boundary, e.g. $\mathrm{H} \%$ for a rising boundary, and $\mathrm{L} \%$ for a falling boundary.

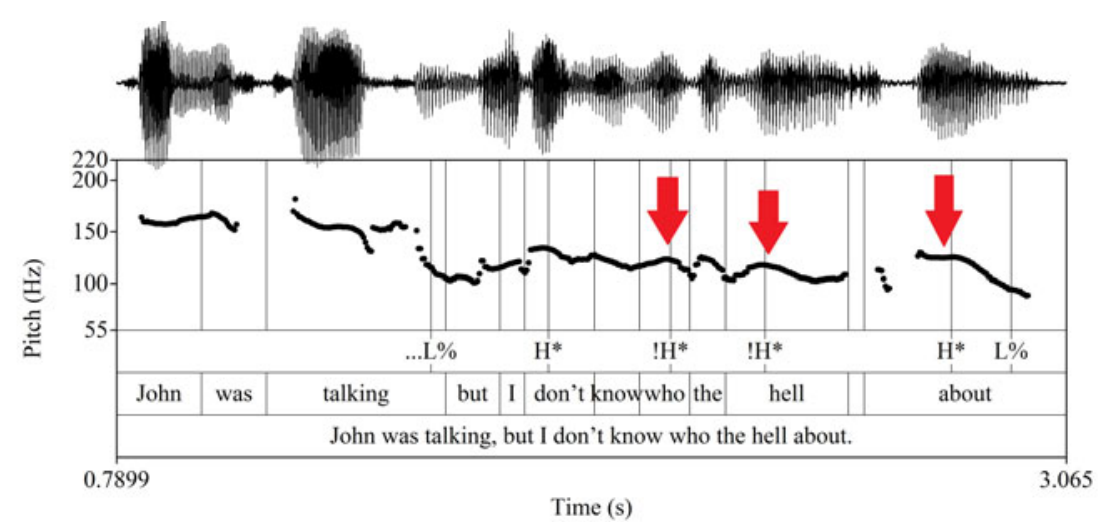

Figure 1

(Colour online) A sample pitch track of a new preposition in swiping+the-hell: The preposition bears the final and the nuclear accent while the-hell bears down-stepped pre-nuclear accent (Speaker 1, male).

In Figure 1, focusing on the clause with swiping, we observe that both the hell and the $w h$-item bear a high pitch accent. The accent on the $w h$-item is realised at a relatively lower level than the preceding pitch accent - maximum pitch on the $w h$-item is $123 \mathrm{Hertz}(\mathrm{Hz})$, and the maximum pitch of the preceding item (i.e. don't $t$ is $134 \mathrm{~Hz}$. This indicates a downstep from the utterance-initial $\mathrm{H}^{*}$ to the accent on the $w h$-item, which is marked with ! on the downstepped tone: ! $\mathrm{H}^{*}$. The high pitch accent on TH is also downstepped, bearing a maximum pitch of $117 \mathrm{~Hz}$, which is relatively lower than the accent on the $w h$-item. The last accentbearing unit in this clause is the preposition about, the maximum pitch of which is $130 \mathrm{~Hz}$. The accent on the preposition is not downstepped, and $\mathrm{P}$ is perceived as the most prominent unit in this clause. The accent on the preposition about is hence an NA. ${ }^{8}$ In this particular example, and in the rest of the tokens with WTH, we observed that $\mathrm{TH}$ always precedes NA.

A sample pitch tack of a swiping construction without TH is given in Figure 2. In this case, the preposition is given in the antecedent clause. Recall from the

[8] Although in this particular example the NA is not a downstepped accent, this does not mean that an NA cannot be downstepped. This is a commonly observed property of prosodically right-prominent languages which also bear intonational phrase-level downstep (we refer the reader to Liberman \& Pierrehumbert 1984 for English, and Truckenbrodt 2007 for an overview of such cases). 
acceptability judgement experiment that similar sentences, against the statements of the previous literature, were considered acceptable.

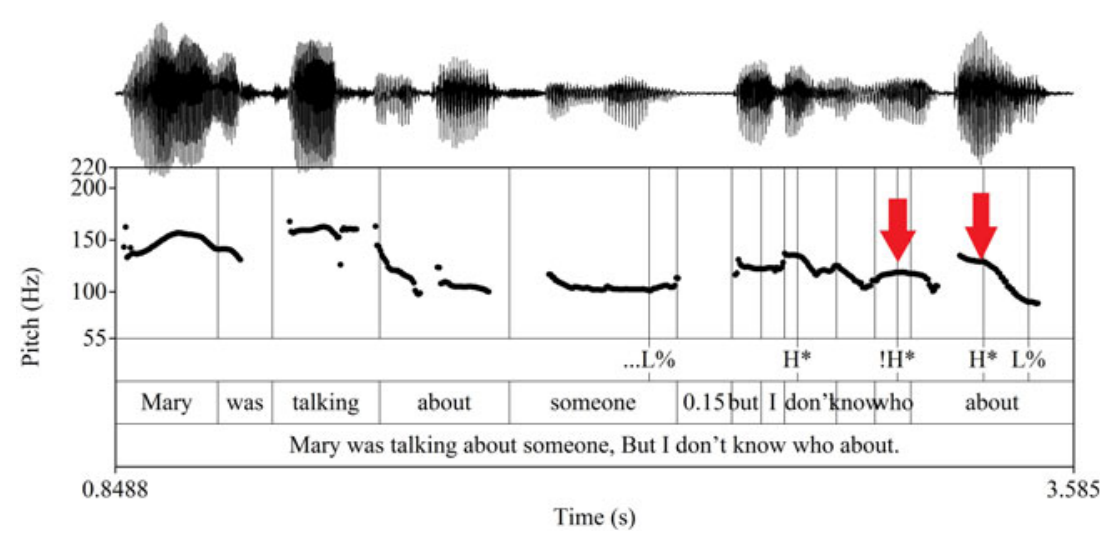

Figure 2

(Colour online) A sample pitch track of a given preposition in swiping: The preposition bears nuclear accent (Speaker 1, male).

In Figure 2, the pitch peak on the preposition that is in the clause with swiping clearly shows that the preposition bears the final and hence the nuclear accent of this clause. This novel observation suggests that the accent on the preposition in swiping structures cannot be related to the information structural status of P. In addition to the accent on about, we also observe that the $w h$-item bears a $! \mathrm{H}^{*}$ tone.

The pitch track of a swiping construction with TH is given in Figure 3. Similar to the previous case, the preposition in Figure 3, which is information structurally given, heads an adjunct PP.

The figure shows the pitch peak on the utterance-final preposition about in the elliptical clause; about hosts the clause's nuclear accent, which makes it the most prominent unit of this clause. We also observe a linguistic pause in the juncture of TH and P. The duration of this pause is $100 \mathrm{~ms}$. On the string of WTH, there are two accents, the latter of which is a downstepped high accent. One of these accents is on the $w h$-item and the other on TH. Similar to the previous case of WTHs presented in this section, in this example, too, we observe that TH precedes the item that bears NA, i.e. an utterance-final preposition.

Following the prosodic examination of the pitch tracks, we conclude that the prepositions in swiping always bear the NA in swiping, regardless of whether or not they are information structurally given. The presence of TH does not affect the location of NA. As such, swiping structures with TH still locates the NA on the preposition. Additionally, TH always precedes an NA-bearing item. Moreover, we also observed that both the $w h$-item, and TH bear accent in swiping, however these are never NA. Lastly, in Figure 3 (and in other similar cases we recorded), 


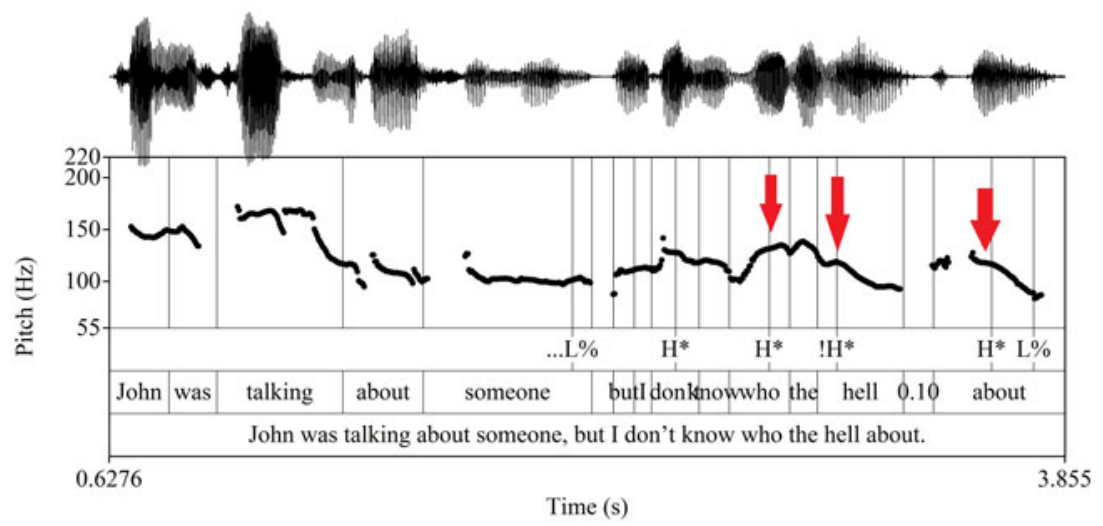

Figure 3

(Colour online) A sample pitch track of a given preposition in swiping+the-hell: The preposition bears nuclear accent and the-hell bears a pre-nuclear accent (Speaker 1, male).

we observed that in a string of $\mathrm{WTH}+\mathrm{P}$ in swiping constructions, there is often a linguistic pause at the juncture of WTH and $\mathrm{P}$, which indicates the presence of a prosodic boundary at this juncture.

Building on the well-attested fact that the preposition in a swiping construction always bears prosodic prominence, Sprouse (2006) suggests that the puzzle in (2) is sourced from a prosodic conflict. In line with Sprouse (2006), we maintain that the licensing conditions that constrain the well-formedness of WTHs are prosodic in nature. However, we show in the rest of this section that Sprouse's (2006) account is untenable. In Section 4, we offer an alternative prosodic account to resolve the puzzle in (2).

In the next subsection, we introduce Sprouse's account. In Section 3.3, we list its shortcomings. In Section 4, we posit a novel prosodic account for why swiping, and not sluicing, is a licit (prosodic) host for WTH.

\subsection{A pioneering study: Sprouse (2006)}

Sprouse (2006) claims that WTH is licensed in swiping as a result of the fact that the accented preposition creates the ideal prosodic environment for WTH. Sprouse's proposal is based on a number of observations and assumptions, all of which we will discuss below.

First, Sprouse's account is based on the observation that the preposition bears accent in the context of swiping. ${ }^{9}$ He claims that the preposition in swiping is

[9] Adopting Gussenhoven's (1984) terminology, Sprouse (2006) refers to the accent under discussion as 'sentence accent'. In terms of the more recent versions of the prosodic structure theory, Gussenhoven's 'sentence accent' roughly corresponds to 'phonological phrase-level 
focus marked, and has a [+Focus] feature. Relating the accent on the preposition and the alleged requirement that the preposition in swiping should be discourse new, Sprouse proposes the ACCENT PRojection PRINCIPLE (APP), which states that every focus domain (i.e. the domain of a focus marked/new item) must bear phrase accent. Since the preposition in swiping bears phrase accent, Sprouse (2006) concludes that the preposition in swiping is contained within a focus domain, and is marked with [+Focus]. As pointed out by Sprouse (2006), this observation is in line with Gussenhoven's (1984) SENTENCE ACCENT ASSIGNMENT RULE in (22).

\section{(22) Guseenhoven's (1984) Sentence Accent Assignment Rule (SAAR)}

If focused, every predicate, argument, and modifier must be accented, with the exception of a predicate that, discounting unfocused constituents, is adjacent to an argument.

The rule in (22) states that as long as they are new/focused, prepositions and adjuncts receive accent and form their own focus/prosodic domains. ${ }^{10}$ Building on Merchant's (2002) observation that the preposition of swiping cannot have an antecedent, hence must be new, Sprouse suggests that the accent on the preposition of swiping is due to the fact that it bears [+Focus], and hence forms its own focus domain, which is in line with the predictions of SAAR about adjuncts.

Secondly, following Gussenhoven's (1984: 29) observation for certain moved $w h$-items, Sprouse assumes that every $w h$-item must bear a focus domain of itself. Unlike the focus domains that are generated by other kinds of arguments, the domain of the $w h$-word crucially cannot host another item.

Drawing on these two assumptions, Sprouse represents the organisation of focus/prosodic domains in swiping as in (23) below, and in sluicing as in (24) (Sprouse 2006: 6 examples (12c) and (12a), respectively). In these and subsequent examples, following Sprouse's (2006) notational system, each focus/prosodic domain is set in square brackets, and each phrasal accent-bearing unit is set in bold.

pitch accent' (see Beckman \& Pierrehumbert 1986 for phonological phrase-level pitch accent, and Gussenhoven 1994 for a revision of SAAR in English), or a 'phonological phrase head' in which accent, being the most prominent unit, is also the head of its prosodic unit (Nespor \& Vogel 1986). To avoid terminological confusion, we translate Sprouse's (2006) 'Sentence Accent' as 'phrase accent', in which 'phrase' refers to a phonological phrase $(\phi)$ in the prosodic hierarchy (see Nespor \& Vogel 1986 for a definition).

[10] Note that for Gussenhoven (and hence Sprouse), each focus domain is also a prosodic domain (in particular a phonological phrase in our terms), simply by virtue of the fact that they bear prosodic prominence/phrase accent, which is a demarcation of phonological phrase formation in languages such as English (see Beckman \& Pierrehumbert 1986 for phrase accent in English, and Gussenhoven 1994 for the correspondence of focus domains and prosodic domains, and that 'focus domain' is the domain of accent placement). As such, 'Gussenhoven relates the presence of a pitch accent strictly to the formation of a prosodic phrase, taking the accent as the head of the phrase' (Féry \& Ishihara 2010: 45). Based on this, we treat the accent-bearing focus domains that are predicted by SAAR as phonological domains that are smaller than intonational phrases/tone groups, i.e. as phonological phrases. 


\section{... [but I don't know][what][about]}

... [but I don't know][what]

Lastly, Sprouse claims that TH cannot bear prosodic prominence/accent. Given Gussenhoven's (1984: 28) statement that any material that does not form its own focus domain (i.e. all items that are given or cannot project accent for some reason) must be contained within the neighboring focus domain, Sprouse predicts that the prosodic environment that is generated in sluicing is prosodically unfit to host TH. This is because TH cannot project its own focus domain, and hence it must be contained within the focus domain of the item adjacent to it.

In sluicing, as illustrated in (25) (from Sprouse 2006), the domain of wh-word is the only domain to which $\mathrm{TH}$ is adjacent. However, the focus/prosodic domains of $w h$-items are suggested not to be able to host other items. Therefore, in sluicing, $\mathrm{TH}$ forms a separate focus/prosodic domain, to the exclusion of the wh-item. However, since every focus domain must bear accent (recall APP), and since TH cannot bear accent, TH in sluicing is prosodically not licensed. The schematic representation of a WTH in sluicing in (25) demonstrates the unacceptable prosodic configuration in which $\mathrm{TH}$ is contained within a focus/prosodic domain, without bearing an accent.

(25) *... [but I don't know][what] [the hell]

(Sprouse 2006: 6 ex. (12b))

Unlike sluicing, the prosodic structure that is generated in swiping is endowed with a focus/prosodic domain that is able to host items such as TH. This host is the domain that is generated by the preposition of swiping, which bears a phrase accent. In (26) (from Sprouse 2006: 6 example (12d)), in addition to the focus/prosodic domain of the $w h$-item, there is another focus/prosodic domain in the vicinity of the TH. This is the domain that contains the preposition. Unlike the $w h$-items, the P's focus/prosodic domain is capable of hosting items other than the accented element. TH is included in the domain of $\mathrm{P}$, which not only satisfies Sprouse's condition that every constituent is contained within a focus domain with an accented item, but also allows TH to remain unaccented, another property that Sprouse attributes to $\mathrm{TH}$.

... [but I don't know][what][the hell about]

Although Sprouse's prosodic licensing account predicts the crucial contrast between the acceptability of WTHs in sluicing and swiping, it is also burdened with a number of shortcomings. Below we list three of these shortcomings, which lead us to posit a novel prosodic account in Section 4 for the licensing of WTHs, not only in elliptical sentences but also in non-elliptical sentences. 


\subsection{Shortcomings of Sprouse (2006)}

The most crucial problem with Sprouse (2006) is its claim that aggressively nonD-linked items reject prosodic prominence/accent, with the help of which the unacceptability of WTHs in sluicing is explained. This claim, however, does not find empirical support. The TH part of a WTH string MAY bear phrasal accent (see also Merchant 2001). The prosodic representation given in Figure 4 below is taken from O'Connor \& Arnold (1973), which depicts the prosody of an utterance that starts with a WTH, in this case what on earth. In the annotation system they employ, prosodically prominent/accented syllables are marked with larger dots. As seen in the annotation, the word earth, which is the last item of the WTH string, is more prominent than the preceding $w h$-item (TH in this case would be annotated with a high pitch accent, $\mathrm{H}^{*}$, in ToBI labelling system of Auto-segmental Metrical theory).

\begin{tabular}{|c|c|c|c|}
\hline What on & EARTH did you do & THAT & for, Peter \\
\hline • • & $\begin{array}{r}\bullet \bullet \bullet \\
\end{array}$ & 9 & \\
\hline low & high & $\mathrm{High} \mathrm{Fa}$ & \\
\hline
\end{tabular}

Figure 4

A sample representation of the intonational contour of what on earth with the British School annotation (O’Connor \& Arnold 1973).

Similar to O'Connor \& Arnold's (2001) observation, the pitch track in Figure 6 below, from our own recordings, shows that TH is not only capable of hosting a high pitch accent, but also this accent may even be more prominent than the $w h$-item that precedes it. In Figure 5, the mean f0 of the vowel of the $w h$-word is $192 \mathrm{~Hz}$, and the mean f0 of vowel of the word hell is $201 \mathrm{~Hz}$. In addition to this difference in the pitch register, while the $w h$-item bears a low pitch accent $\left(\mathrm{L}^{*}\right)$, TH bears a high pitch accent $\left(\mathrm{H}^{*}\right)$.

A second problem with Sprouse (2006) concerns the prediction about the behaviour of given prepositions. Gussenhoven (1984: 29) states that moved whitems tend to form an independent focus/prosodic domain only when the moved $w h$-item is not followed by given material. When the $w h$-item is followed by given material, any constituent that is [-Focus] is included within the focus domain of the $w h$-item. This by itself predicts in the theory of Sprouse (2006) that when given in the antecedent clause, WTHs should be licensed in sluicing. This is not borne out:
A: Who the hell did John kiss?
B: *I don't know who the hell. 


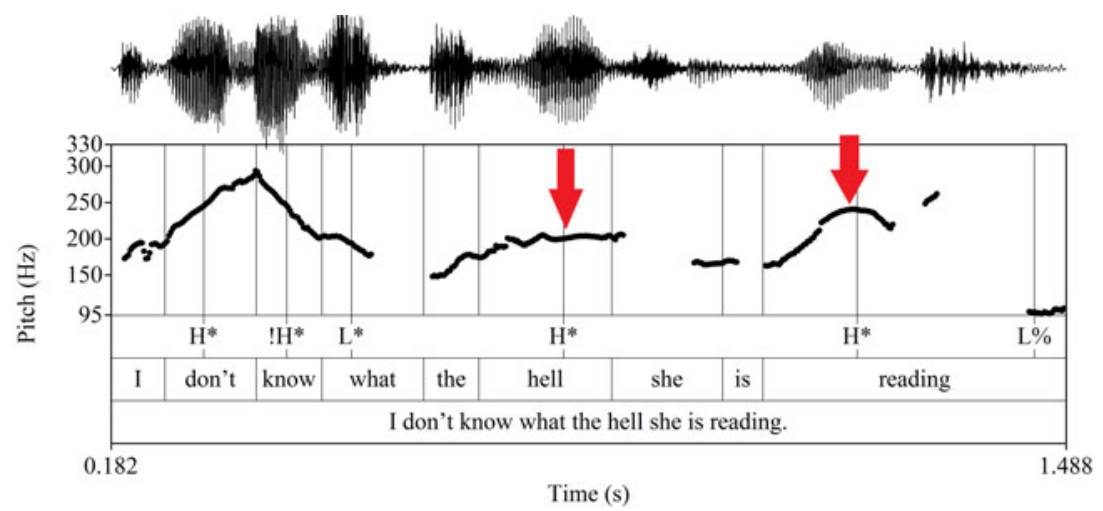

Figure 5

(Colour online) A sample of what the hell: The hell is accented (Speaker 3, female).

Besides this, given Gussenhoven's generalisation, Sprouse claims that the preposition in swiping bears accent because it is always new, and hence it cannot be fused into the domain of the $w h$-item.

As we have shown in Section 2, the preposition in swiping does not always have to be new. Discourse given prepositions are also perfectly acceptable in swiping. Thus, the accent on the preposition that the previous literature (including Sprouse (2006)) has observed cannot be related to its information structural status. An additional problem is that although information structurally given material may be fused into the focus/prosodic domain of the wh-item, as Gussenhoven states, this does not take place in swiping (recall Figure 2 above). Regardless of the fact that the preposition is information structurally given, see (28a), a constituency that fits to the representation in e.g. (28b) is not attestable, an observation that comes from Merchant (2002). This behaviour cannot be explained by Sprouse's account, as there is nothing that would motivate the accent on an information structurally given preposition.

(28) (a) ... about something, [but I don't know][what] [about]

(b) *... about something, [but I don't know][what about]

The last problem that the proposal in Sprouse (2006) encounters is that it predicts a non-attested prosodic grouping for WTH+preposition. In Sprouse's representation of WTH in (26) - repeated in (29) below - the wh-word and TH are contained within separate focus/prosodic domains. This implies the presence of acoustic and tonal cues that marks such a disjoint prosodic phrasing. In fact, Sprouse's account predicts such a prosodic detachment not only in the cases of swiping but also in all occurrences of WTHs. Sprouse's prediction is schematized in (30), in which the $\mathbf{X}$, which follows $\mathbf{T H}$, is an accented item that has the feature [+Focus]. 
... [but I don't know][what][the hell about]

$\ldots\left[\boldsymbol{w h}\right.$-item][aggressively non-D-linked phrase $\left.+\mathbf{X}_{[+ \text {FOCUS }]}\right]$

Such a split prosodic grouping of $w h$-item and $\mathrm{TH}$ is simply not attested in the samples we collected. In fact, our British English consultants considered such a split grouping in swiping such as (31), and non-swiping environments such as (32), to be markedly unnatural and forced. The acoustic analysis of the recorded samples of these sentences also showed that there is no such prosodic boundary between the $w h$-item and the TH string (consider Figure 6).

(31) \#... [I don't know] [who] [the hell to]

(32) \#[What $][$ the hell happened $]$ ?

From a syntax-prosody mapping point of view, the avoidance of a split parse is expected. This is because in syntax, wh-item and TH form a complex head, and this syntactic head is expected to be mapped into a prosodic domain.

Furthermore, Sprouse's claim that the TH and the preposition in swiping are contained within a single prosodic domain - as illustrated in (31) - is not attested, either. In fact, the acoustic and tonal analyses of such strings clearly show that the preposition is parsed separately from WTH. Figure 6 illustrates the prosody of WTHs in swiping, where there is no metrical and audible boundary between the $\mathrm{W}$ and the $\mathrm{TH}$, but there is a clear boundary between WTH and P.

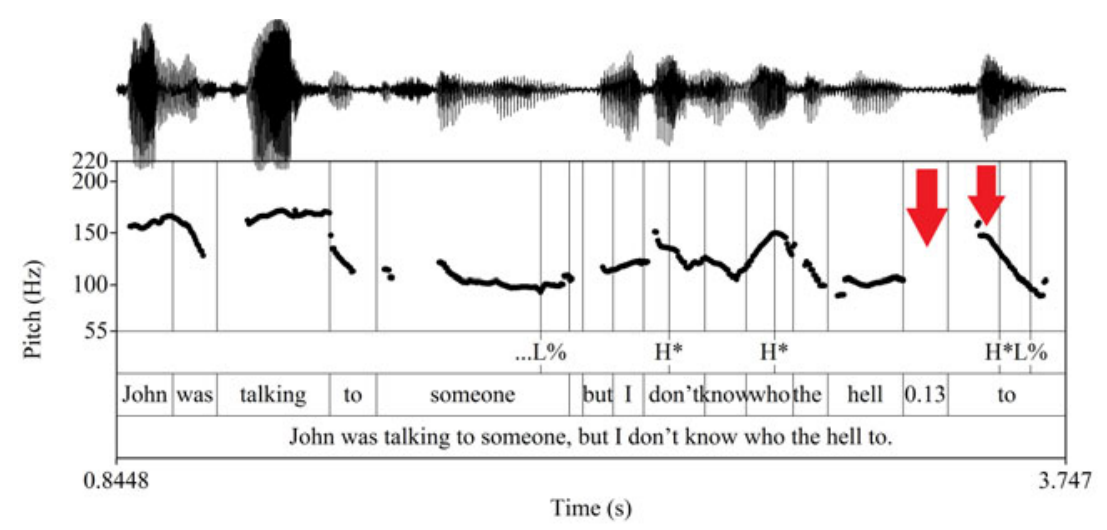

Figure 6

(Colour online) A sample of what the hell in swiping: The preposition is preceded by a pause (Speaker 1, male).

As seen in Figure (6), the preposition is separated from the preceding string hence from the $\mathrm{TH}$ - with an audible linguistic pause (duration of the pause is 130 $\mathrm{ms}$ ). The pause immediately follows the /1/ phoneme of the TH and ends with the onset of the preposition, which is clearly visible in the waveform. Note that such 
a pause was present in most of the tokens we recorded. Given Sprouse's prosodic representation, such a pause is not expected, as TH is assumed to be fused into the prosodic domain of the preposition.

\subsection{Interim summary}

Focusing on the prosodic properties of WTHs and the preposition in swiping, we have established the prosodic profile of the construction and made two important observations. First, WTHs may bear accent but cannot bear nuclear accent. Second, the preposition in swiping does bear nuclear accent, crucially not only when it is new but also when it is given. This indicates that the prominence on the preposition is not for marking focus.

Having ruled out syntax and semantics as possible sources for the unacceptability of WTHs in sluicing in Section 2, we now conclude that prosodic factors may play a role in licensing WTHs, in line with Sprouse (2006). Crucially, however, the prosodic account provided in Sprouse (2006) is not fully successful in accounting for the wider range of the data, and a number of its assumptions are not empirically supported. In the next section, we therefore present a prosodic account inspired by Sprouse (2006), but differing from it in certain ways, to predict the distribution of WTHs in not only elliptical clauses but also in non-elliptical ones.

\section{A NOVEL PROSODIC ACCOUNT OF WTH IN SWIPING/SLUICING}

\subsection{Prosodic licensing of WTH in swiping/sluicing}

Following Sprouse (2006), we claim that the well-formedness of WTHs in British English is prosodically conditioned. However, dissimilar to Sprouse's claim, our proposal is based on two non-trivial facts that we reported in previous sections: (i) WTHs CAN bear accent but not nuclear accent, and (ii) the prepositions in swiping are accented, but this cannot be because of their information structural status.

Our account has two main ingredients. The first concerns the well-formed prosodic distribution of WTHs. The second concerns the nature and source of the accent placement on the preposition in swiping constructions.

We propose that there is a very strictly observed prosodic licensing condition on the well-formedness of WTHs in British English, which is active, not only in elliptical sentences but also in non-elliptical sentences. The condition we propose is as follows:

\section{Prosodic licensing condition of WTHs in British English}

A WTH must precede the NA.

The condition in (33) states that the use of WTHs is well-formed in a sentence as long as it precedes nuclear accent-bearing item of that sentence. This condition also makes a number of predictions, one of which is that a WTH in sentencefinal position is not well-formed, as a sentence-final WTH cannot be followed 
by NA. Similarly, when a WTH bears an NA, or follows an NA, (33) predicts unacceptability. This is simply because none of these prosodic configurations are fit for the well-formedness of WTHs; see (34a) below for the schematic representation of the former and (34b) for the latter. When a WTH is followed by any item capable of bearing a nuclear accent, the required prosodic environment is obtained for it; this is schematised in (34c).

(34) (a) WTH as the nucleus: *... $\mathrm{WTH}_{\mathrm{NA}} \ldots$

(b) WTH as the post-nucleus: *NA ... WTH ...

(c) WTH as the pre-nucleus: ... WTH ... NA ...

As for the assignment of nuclear accent in British English, we adopt Cinque's (1993) syntax-oriented STRESS DEEPEST algorithm (SD), which states that, in information structurally uniform sentences, the syntactically deepest constituent in a clause receives nuclear accent, and is perceived as the most prominent unit at the intonational phrase-level. ${ }^{11}$ By INFORMATION STRUCTURALLY UNIFORM sentences, we mean cases in which all items in a sentence are all-new or all-given. An INFORMATION STRUCTURALLY IMBALANCED sentence is a sentence with focused/given items, in which case the sentence exhibits information structure related prosodic grouping and tone insertion in intonation languages such as English and Dutch (see Zubizarreta 2016). In cases of all-new or all-given contexts, the sentence bears syntactically navigated default NA (see Büring 2016, and references in there).

To discuss the NA placement in the pronounced parts of a clause with ellipsis, we adapt SD to clauses with ellipsis. We suggest that the assignment of nuclear accent in clauses with ellipsis in British English is identical to information structurally homogeneous clauses without ellipsis. As such, unless they bear contrastive information, all items that are realised outside of the ellipsis site are considered as information structurally uniform; hence SD, which is a syntaxoriented default nuclear accent placement algorithm, is active.

Importantly, we claim that, in elliptical clauses, SD applies only to the nonelided part of the clause. This needs to be stated explicitly because, unlike in nonstructural approaches to ellipsis (Culicover \& Jackendoff 2005, Sag \& Nykiel 2011), SD applying to the non-elided material is not self-evident in structural approaches to ellipsis, which countenance the concept of an ellipsis domain and silent structure within it. In structural approaches, the DEEPEST item that is considered for prominence placement is not necessarily the syntactically deepest item in the entire clause. In (35), we therefore present the nuclear accent assignment

[11] Nothing hinges on our use of Cinque's (1993) syntax-oriented nuclear accent assignment algorithm. Other algorithms that abstract away from word-order-based dependencies and that make recourse to argument structure and syntactic composition - such as Truckenbrodt's (1995) Stress-XP - would yield the same results. Gussenhoven's (1984) SAAR may not be optimal as it still refers to linear adjacency rather than phrase structural relations. 
algorithm that we advance for elliptical clauses in structural approaches, for which we may speculate that NA placement takes place post-ellipsis. ${ }^{12}$
Nuclear accent assignment in clauses with ellipsis in British English
In clauses with ellipsis, assign nuclear accent to the structurally deepest item that is outside of the ellipsis domain.

The algorithm in (35) is architecturally motivated given that, in the reverse $\mathrm{Y}$ model of grammar, phonological operations apply after the insertion of vocabulary items (Embick \& Noyer 2007). As such, only those syntactic terminals that are not elided are visible to phonological operations (see e.g. Nespor \& Vogel 1986, Kentner 2007 and Truckenbrodt 2013, for the conclusion that 'phonetically empty' material such as the ellipsis site is ignored by prosody).

Returning to the puzzle in (2), with the condition in (33) and the algorithm in (35), we can account for why WTHs are not allowed in sluicing, but are allowed in swiping.

In sluicing, the deepest constituent that is outside of the ellipsis domain is the $w h$-item. As a result of its structural distribution, the $w h$-item receives nuclear accent in sluicing constructions (36). When a TH adjoins the $w h$-item (as in 36b), the entire string of the WTH receives the nuclear accent. This fails to satisfy the prosodic well-formedness condition in (33).

(a) NA in sluicing: ...Wh $h_{\mathrm{NA}}$

John kissed somebody, but [CP1 I don't know [CP2 [DP who $\left.]_{\mathrm{NA}}\right]$ ].

(b) NA in sluicing with WTH: *... $\mathrm{WTH}_{\mathrm{NA}}$

*John kissed somebody, but [CP1 I don't know [CP2 [DP who the hell] $\left.]_{\mathrm{NA}}\right]$.

Swiping creates the desired prosodic environment to license WTH, simply by virtue of the fact that the preposition, which linearly follows WTH, bears an NA as a result of (35). This is because in swiping the structurally deepest item that is outside of the ellipsis site is the preposition and not the wh-item or WTH - see (37).

[12] Note that similar to clauses without ellipsis, the pronounced parts of elliptical clauses may also bear focused/given items, such as the case of $v$ P-ellipsis given in (i).

(i) I know who [John $]_{F / N A}$ kissed, but I don't know who [Bill $]_{F / N A}$ did.

Similar to their non-elliptical counterparts, we assume that in such cases an information structure related tonal organisation and prosodic phrasing procedure blocks the assignment of the default syntax-oriented nuclear accent placement. See Ladd (1996) among many others for the difference between the default nuclear accent placement and information structure related prominence placement. The elliptical cases that are discussed in Sprouse (2006) and in the present subsection of this paper do not exhibit focused/given items (but see Section 4.2 for samples of focus related nuclear accent placement in clauses with a WTH). 
(37) (a) NA in swiping: ... Wh ... [Preposition $]_{\mathrm{NA}}$

John talked to somebody, but [CP1 I don't know [CP2 [DP who] [to $\left.]_{\mathrm{NA}}\right]$.

(b) NA in swiping with WTH: ... WTH ... [Preposition $]_{\mathrm{NA}}$

John talked to somebody, but [CP1 I don't know [CP2 [DP who the hell] [PP to $\left.\left.]_{\mathrm{NA}}\right]\right]$.

Similarly, a WTH is prosodically well-formed in any non-elliptical context, as long as the string that follows the WTH bears nuclear accent. In an example such as (38), nuclear accent falls on the lexical verb reading. See Figure 5 above for the attested prosody of this example.

NA in a non-elliptical clause with WTH: ... WTH ... NA ...

I don't know [CP [DP what the hell] [... she is [ ${ }_{\mathrm{P}}$ reading $\left.\left.]_{\mathrm{NA}}\right]\right]$.

In the light of new observations presented in this paper, the data are accommodated better in our account than in Sprouse's (2006) prosodic account. First, in our account, the prominence that is observed on the preposition of swiping is not due to its information structural status, but due to its syntactic position. By employing Cinque's (1993) stress deepest algorithm, we predict prominence on the preposition regardless of whether or not it is given in the antecedent clause. Secondly, in our account, the prosodic well-formedness of WTHs is not contingent upon its ability to bear accent. As such, the condition in (33) makes no reference to the accentability of WTHs, or, more specifically, TH. The only condition on the prosodic well-formedness of WTHs is its prosodic distribution relative to the location of nuclear accent. As long as (33) is satisfied, various prosodic realisations of WTHs, including the versions in which TH bears accent, are easily accommodated in our account. Lastly, our account does not appeal to the presence of counter-intuitive prosodic chunks, such as the detached prosodic grouping of the $w h$-item and the string of $\mathrm{TH}$.

In this section, we set out a novel prosodic account that successfully predicts the well-formedness of WTHs in swiping, and unacceptability of it in sluicing. The prosodic well-formedness condition that we propose in (33) states that nuclear accent must follow WTH, making no specific reference to ellipsis. Hence, we expect this condition to be active for all cases of WTHs, i.e. not only in sentences with ellipsis but also in sentences without ellipsis.

So far we have focused on how certain cases of ellipses, such as sluicing, accidentally create non-ideal prosodic environments for licensing WTHs. In the next section, we present more examples from elliptical clauses in support of the relevance of our account. In addition to this, we show that (33) seeks to be satisfied in non-elliptical clauses of British English, too.

\subsection{Prosodic licensing of WTHs beyond swiping/sluicing}

In information structurally imbalanced cases, which require the marking of focus and givenness, the default syntax-oriented NA placement algorithm in (33) above 
is overridden. In such cases, the NA is aligned with the item that bears information structural focus, in languages such as British English and Dutch. In such cases, the area that follows the focused item (hence NA) is deaccented (see Féry 2011 for an overview).

Our account makes certain predictions for such cases, namely those with focus related NA placement and givenness related deaccentuation. In particular, our account predicts that in cases when all the items that follow WTHs are discourse given, and deaccented, WTHs are not licensed, as they do not precede an NA. This prediction is borne out. In (39i) below, the items that follow WTHs in the second clauses are given in the clauses that precede them. This leads to a prosodic environment in which a WTH does not precede NA. Givenness related deaccentuation is marked with italics, focus related NA is marked with capitals. Note that the unacceptability of (39i) should be attributed to the accentuation profile of the second half of these clauses, and not some other factor, such as redundant repetition of the given information, simply because, as seen in (39ii), the same sentences without TH are acceptable regardless of the repetition.

(i) Non-elliptical clause (focus/given context): A WTH bears nuclear accent

(a) */?I know that he saw someone, but I don't know [WHO THE HELL $]_{\mathrm{F} / \mathrm{NA}}$ he saw.

(b) *Surely, something was stolen, but I don't know [WHAT THE HELL]F/NA was stolen.

(ii) Non-elliptical clause (focus/given context): A WH bears nuclear accent

(a) I know that he saw someone, but I don't know [WHO $]_{\mathrm{F} / \mathrm{NA}}$ he saw.

(b) Surely, something was stolen, but I don't know [WHAT] $]_{\mathrm{F} / \mathrm{NA}}$ was stolen.

In (39), not bearing focus or any contrastive information, the strings he saw and was stolen in the second clauses are deaccented as a result of the prosodic marking of givenness in British English. In the unacceptable cases in (39), the WTH bears an NA, which fails to satisfy (33) and the sentences are rendered as unacceptable. ${ }^{13}$

A case known as why-stripping (Ortega-Santos, Yoshida \& Nakao 2014) is another elliptical environment in which the WTH is prosodically licensed due to focus related NA placement. Consider (40):

Elliptical clause (why-stripping): A WTH precedes nuclear accent

A: John called Bill.

B: Why the hell BILL $L_{\mathrm{F} / \mathrm{NA}}$ ?

[13] Similar judgements were reported to us by our consultants, when they were asked to pronounce WTHs with emphasis and deaccent the following area. 
In (40B), the WTH is followed by a discourse given item, i.e. the object of the antecedent clause, Bill. However, regardless of the fact that it is given, Bill still bears the NA due to the fact that it bears a focal contrast. ${ }^{14}$ As our account predicts, the utterance in (40B) is acceptable as it satisfies the prosodic wellformedness condition in (33).

Another elliptical case in which a WTH is prosodically well-formed is the case of $w h$-stripping. Similar to $w h y$-stripping, in $w h$-stripping, the item that follows the wh-word exhibits focus related NA. In (41), the constituent that follows the $w h$-item, i.e. the preposition after, bears focus related NA.

\section{Elliptical clause (wh-stripping): A WTH precedes nuclear accent}

Tell me who submitted their abstracts BEFORE the deadline, and who the

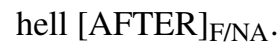

Since WTH precedes the NA-bearing item, it is prosodically licensed, and the sentence is acceptable.

We also predict that amalgams such as (42a) (Lakoff 1974) are not capable of hosting a WTH (see (42b)), regardless of the fact that more phonologically contentful material follows WTH.

\section{(42) Amalgams: A WTH receives the NA of the intonation phrase of the parenthetical}

(a) John was caught selling - I could not care less to [who $]_{\text {NA-parenthetical }}$ -3 kilos of [heroin] NA-host

(b) *John was caught selling - I could not care less to [who the hell $]_{\text {NA-parenthetical }}-3$ kilos of $[\text { heroin }]_{\text {NA-host }}$

This is because such clausal parentheticals are parsed as independent intonational phrases in English (see Dehé 2014). Being the last accent-bearing unit in that intonational phrase, a WTH has to host the NA of its clause. This is a prosodic environment that we predict to be ill-formed for hosting a WTH.

Lastly, our account converges with the observation that aggressively non-Dlinked phrases cannot modify in-situ wh-words (Pesetsky 1987). In English, the NA aligns with the in-situ $w h$-word (see Truckenbrodt 2013). This is exactly the prosodic configuration in which our account predicts the use of $\mathrm{TH}$ to be unacceptable. The example in (43) demonstrates the unacceptable case of an echo question with WTH. ${ }^{15}$

[14] See Ortega-Santos et al. (2014) for the observation that the phrase following why in such elliptical clauses normally receives focus related NA and is contrastively focused even though it is given in the previous discourse.

[15] Evidently, violation to the prosodic well-formedness condition given in (33) is not the only source of unacceptability here. See Den Dikken \& Giannakidou (2002) for semantic reasons for why WTHs are not licensed in echo questions. 

A: John gave Dracula a kiss.
B: *John gave [WHO THE HELL $]_{\mathrm{NA}}$ a kiss?

In this section, we have discussed a number of acceptable and unacceptable cases of WTH, in which the NA is located on or after WTH due to information structural reasons. We have seen that the prosodic well-formedness condition in (33) successfully predicts acceptability of a number of constructions with or without ellipsis. That WTH is prosodically ill-formed in sluicing constructions in British English is due to two factors, (i) the fact that WTHs cannot bear NAs, and (ii) that, in information structurally neutral cases, the syntactically deepest item in a clause receives the NA in English. Although the second factor is a well-established observation about English prosodic grammar, the question why a WTH rejects an NA has not been discussed yet. Although we do not have a definitive answer as to why a WTH rejects nuclear accent, it seems that this property is common to other pragmatically loaded phrases with an expressive content in other languages, too.

\section{EXTENDING THE SCOPE OF OUR ACCOUNT: EPITHETS IN DUTCH}

In this section, focusing on Dutch, we demonstrate that, similar to the British English WTH, wh-item+epithet noun constructions in Dutch also cannot bear an NA. We account for this behaviour with the same prosodic well-formedness condition that we proposed for the British English WTHs. ${ }^{16}$

Prosodically, Dutch and English are similar to one another. In Dutch, too, the item that bears the final accent in an intonational phrase is perceived as the nuclear accent-bearing item of that intonational phrase. In terms of its prosodic typology, Dutch is an intonation language, too. As such, the prosodic

[16] Note that Dutch aggressively non-D-linked wh-phrases, such as wie in hemelsnaam 'who in heaven's name' does not share the property of British English WTH that they cannot occur in sluicing, as van Craenenbroeck (2010b) points out:

(i) A: Je zou iemand kunnen bellen.

you would someone can.INF call.INF

'You could call someone.'

B: Wie in hemelsnaam?

who in heaven's.name

'Who in heaven's name (could I call)?'

The well-formedness of (iB) stems from an independent difference between the two languages. The fact that in hemelsnaam, unlike the hell and other TH items in British English, is not a head-level modifier, and can occur in various positions in the clause, final and nonfinal alike. It can occur at the very end of the clause, as example (ii) shows, which we believe corresponds to adjunction of in hemelsnaam to the entire clause on the right. We contend that (i) is derived from an adjunction structure in (ii). Evidently, in hemelsnaam does not have the requirement that it should be followed by NA in its clause.

(ii) Wie zou ik kunnen bellen, in hemelsnaam? who would I can.INF call.INF in heaven's.name Lit.: 'Who could I call in heaven's name?' 
typography of an intonational phrase is bound to vary for information structural reasons (i.e. to mark foci, topics, and given parts of utterances), in information structurally imbalanced contexts. With this knowledge in mind, we introduce the $w h$-item+epithet constructions in the relevant contexts.

Dutch allows complex $w h$-phrases in sluicing constructions with a non-Dlinked reading of the $w h$-constituent:

(44) Jan gaat morgen lezen, maar ik weet niet welke Jan FUT tomorrow read.INF but I know not which boeken $_{N A}$ [hij gaat lezen].

(Dutch) books he FUT read.INF

'Jan will read tomorrow, but I don't know what books.'

With this interpretation, the noun in the string welk $(e)+\mathrm{N}$ is accented (if the interpretation is D-linked, accent falls on welk(e) 'which'; note that $-e$ is an agreement ending). The same holds for welk $(e)+\mathrm{N}$ constituents that contain an expressive noun and which are used as an epithet. Some instances of welk $(e)+\mathrm{N}_{\text {epithet }}$ are listed in (45).
(a) welke idioot / sukkel / flapdrol / stommerik which idiot dope wally blockhead 'which idiot'
(b) welke slimmerik
which know.it.all
'which know-it-all'
(Dutch)

What is interesting for the current discussion is the fact, illustrated in (46), that welk $(e)+\mathrm{N}_{\text {epithet }}$ in sluicing constructions is unacceptable, similar to WTH in British English.

(46) [Context: I was under the impression that everyone will support us. But alas...]

*Een paar mensen hebben tegen gestemd, ik vraag me a couple people have against voted I ask me af welke idioten.

(Dutch)

PRT which idiots

Lit.: 'A couple of people voted against, and I wonder which idiots.'

Consequently, we claim that, just as WTH in British English, welk $(e)+\mathrm{N}_{\text {epithet }}$ in Dutch requires a specific prosodic distribution, and that the unacceptability of (46) is due to the fact that the prosodic well-formedness condition on welk $(e)+\mathrm{N}_{\text {epithet }}$ is not satisfied in sluicing constructions. The well-formedness condition we propose for welk(e)+N $\mathrm{N}_{\text {epithet }}$ is given in (47), which has the identical prosodic distribution that is required for the prosodic well-formedness of WTH phrases in British English. 
(47) Prosodic licensing condition of welk(e) $+N_{\text {epithet }}$ in Dutch

A welk $(e)+\mathrm{N}_{\text {epithet }}$ must precede the NA.

By employing (47), we can now account for the unacceptability of the use of welk(e)+ $\mathrm{N}_{\text {epithet }}$ in sluicing constructions as shown in (48). In Dutch, too, being syntactically the most deeply embedded item on the phonologically realized part of the elliptical clause, $\mathrm{N}_{\text {epithet }}$ receives NA. Since, in such a configuration, welk $(e)+\mathrm{N}_{\text {epithet }}$ does not precede NA, (47) is not satisfied, which leads to the unacceptability of the resulting structure in (49).

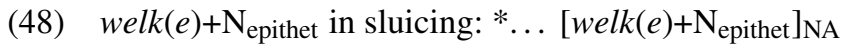

[Context: I was under the impression that everyone will support us. But alas...]

*Een paar mensen hebben tegen gestemd, ik vraag me af a couple people have against voted I ask me PRT welke [idioten $]_{\mathrm{NA}}$. (Dutch)

which idiots

Lit.: 'A couple of people voted against, and I wonder which idiots.'

The condition in (47) also predicts that as long as the NA follows a welk $(e)+\mathrm{N}_{\text {epithet }}$, the structure is considered as acceptable. This prediction is borne out. The example in (49) is a case of sluice-stripping, in which the string welk $(e)+\mathrm{N}_{\text {epithet }}$ is followed by a contrastively focused item that bears focus related NA, i.e. the preposition tegen 'against'.

(49) welk $(e)+\mathrm{N}_{\text {epithet }}$ in sluice-stripping: ... welk $(e)+\mathrm{N}_{\text {epithet }}[\text { Focused item }]_{\mathrm{NA}}$

Een paar mensen hebben tegen gestemd, ik zou heel erg a couple people have against voted I would very much graag willen weten welke mensen VOOR hebben gestemd, en gladly want.INF know.INF which people for have voted and welke idioten $[\text { TEGEN }]_{\text {F/NA. }}$ (Dutch)

which idiots against

Lit.: 'A couple of people voted against, and I would really like to know which people voted for and which idiots against.'

Figure 7 presents the pitch track of (49), which we elicited from a native Dutch speaker. $^{17}$

As seen in Figure 7, the contrastive focus-bearing item tegen 'against' in the elliptical clause also bears the final accent of this clause. As such tegen hosts the nuclear accent of the elliptical clause, which is also perceived as the most prominent unit of this clause. On the string welk $(e)+\mathrm{N}_{\text {epithet }}$, we observe a

[17] For the transcription of Dutch contours, we followed ToDI annotation conventions (Gussenhoven 2005). 


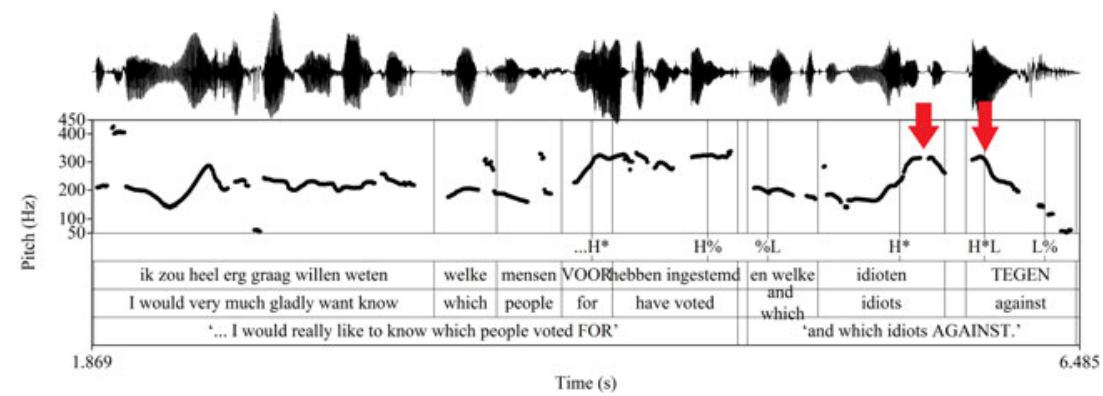

Figure 7

(Colour online) A sample pitch track of welk $(e)+\mathrm{N}_{\text {epithet }}$ followed by a contrastively focused item: Nuclear accent follows welk $(e)+\mathrm{N}_{\text {epithet }}$ (female speaker).

pre-nuclear accent, which is accommodated in our account due to the fact that the prosodic licensing condition in (47) does not rule out accent placement on

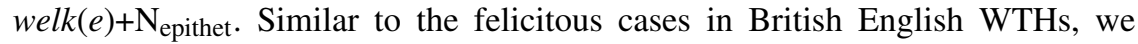
observe that welk $(e)+\mathrm{N}_{\text {epithet }}$ precedes the item that bears NA, hence (47) is satisfied.

Similarly, in (50), the negation morpheme niet 'not' in the elliptical clause bears the NA as it marks a contrast with the antecedent clause. Since niet follows welk $(e)+\mathrm{N}_{\text {epithets }}$, the sentence is prosodically well-formed (see Figure 8).

(50) Ik zou heel erg graag willen weten welke mensen wel I would very really please want.INF know.INF which people AFF hebben ingestemd, en welke stommeriken $[\mathrm{NIET}]_{\mathrm{F} / \mathrm{NA}}$. (Dutch) have concurred and which idiots not

Lit.: 'I would like to know who concurred and which idiots did not.'

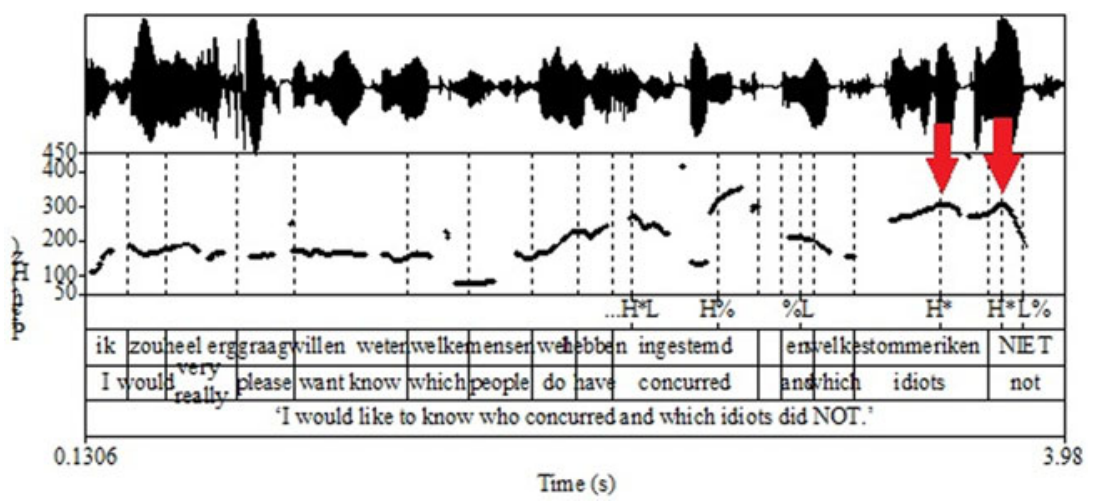

Figure 8

(Colour online) A sample pitch track of welk $(e)+\mathrm{N}_{\text {epithet }}$ followed by a contrastively focused item: Nuclear accent follows welk $(e)+\mathrm{N}_{\text {epithet }}$ (female speaker). 
In Figure 8, this time the focus-bearing item (which is also the host of the NA) in the elliptical clause is niet 'not', similar to the case in Figure 7. On the string welk $(e)+\mathrm{N}_{\text {epithet }}$, we observe a pre-nuclear accent.

Similar to WTH in British English, in Dutch, if welk $(e)+\mathrm{N}_{\text {epithet }}$ is followed by a domain of deaccentuation, then the sentence becomes degraded, due to the fact that welk $(e)+\mathrm{N}_{\text {epithet }}$ does not precede the NA. In (51), the string that follows welke slimmerik is deaccented (and set in italics) as it is given in the antecedent clause. This renders welke slimmerik as the host of the NA. Thus this prosodic environment fails to satisfy the condition in (47).

?/*Iemand heeft deze code gekraakt, maar ik weet niet welke someone has this code cracked but I know not which

$[\text { SLIMMERIK] }]_{\text {F/NA }}$ deze code heeft gekraakt. (Dutch)

know.it.all this code has cracked

'Someone has cracked this code, but I don't know which know-it-all has cracked this code.'

The data covered in this section show that the prosodic well-formedness condition we proposed in this paper might apply to a broader set of items (and languages) than British English aggressively non-D-linked items only. On the basis of the British English and the Dutch data, we could speculate that the condition we identified applies to (negatively) evaluative (expressive or taboo) $w h$-phrases containing items that are understood in their non-literal meaning. To find out whether this is the right characterisation, more languages and expressive constructions would need to be analysed in the manner we have done in this paper. While we leave this for future research, we end by stressing the point that whatever source (33) has, it should not be seen as a universal condition applicable to all languages, as we are currently aware of at least one language in which (33) does not apply to WTH phrases: Hungarian.

As we mentioned in Section 2, WTHs are well-formed in sluicing in Hungarian. In (52), we repeat example (21) above illustrating this for sluicing (Hungarian has no swiping as the language lacks prepositions):

(52) Jani megjavította a kocsit, de nem tudom, Jani PRT.fixed the car.ACC but not know.1SG

mi a bánattal. (Hungarian)

what the sorrow.INST

Lit.: 'Jani fixed the car, but I don't know what the hell with.'

Importantly, a bánat 'the sorrow' and its ilk closely resemble the hell in British English, not only in their interpretation but also in their morpho-syntactic status and complexity: they are head-level elements that are attached to a simplex whhead. Evidence comes from morphological marking (53): the exponent of case and the plural morpheme appear at the end of the wh-the- $\mathrm{N}$ sequence (such markers always show up after the head noun in nominal constituents) (53a). These markers 
cannot appear on the $w h$-item alone (53b) or on both the $w h$-item and the TH element (53c), as would be the case if the $\mathrm{TH}$, for example, was an (appositive) phrasal modifier of the $w h$-phrase. This morphological behaviour therefore ties in with the fact that wh-the-N is a nominal head.
(a) mi a bánat-tal (Hungarian)
what the sorrow-INST
(b) *mi-vel a bánat
what-INST the sorrow
(c) *mi-vel a bánat-tal
what-INST the sorrow-INST

The fact that a WTH is well-formed in sluicing in Hungarian does not come as a surprise if the well-formedness of sluicing with WTHs is governed by a prosodic condition (as we argue in the paper) and is thus bound to the conditions of language-specific prosodic grammars. Hungarian is known to be prosodically dissimilar to English: the tonal organisation of an intonational phrase is entirely different in that nuclear accent is not sentence-final but sentence-initial and is not calculated on the basis of Cinque's stress deepest algorithm, but is always carried by the syntactic focus constituent, which is the wh-phrase in (53) (É. Kiss 2002, Szendrői 2003, Mycock 2007; see also Zubizarreta 1998, Kahnemuyipour 2004 on Cinque's SD not being universal). As WTH phrases are licit in sluicing constructions in Hungarian with WTHs receiving the most nuclear accent, we claim that in Hungarian, nuclear accent can align with WTHs, contrary to what we see in British English. We attribute this difference to the fact that the prosodic grammars of the two languages involve differing, language-specific rules and constraints.

The behaviour of WTHs in Hungarian suggests that there is cross-linguistic variability in the licensing of WTH constructions. This is expected in our account, since the licensing condition we offer in (33) is prosodic in nature, and hence is bound to the conditions of language-specific prosodic grammars.

\section{CONCLUSION}

In this paper we have investigated the reasons why a WTH is licit in swiping but not in sluicing in British English. Considering the syntactic and semantic characteristics of sluicing/swiping, we discussed whether the dichotomy in the acceptability of WTHa is sourced from a conflict between the syntactic/semantic properties of sluicing/swiping and syntactic/semantic licensing conditions on WTHs. We concluded that neither a syntactic licensing condition nor a semantic one can successfully account for this dichotomy. Eliminating these two options, we discussed if the peculiar prosodic environments that arise in the context of sluicing/swiping may be the source of this dichotomy.

Following the results of three acceptability judgment tasks and prosodic observations, we have shown that the $w h$-item bears nuclear accent in sluicing 
but not in swiping, and that accent placement in the elliptical clauses cannot be predicted by recourse to accent placement in relation to information structure. We concluded that a prosodic licensing condition on WTH may be the source for the difference in acceptability. We then discussed Sprouse's (2006) prosodic licensing condition on WTHs in sluicing and swiping. We showed that this condition does not hold and we developed a novel prosodic account instead.

In our account, adapting Cinque's (1993) stress deepest algorithm to British English elliptical clauses, we predicted the prosodic difference in the realisation of the $w h$-item in sluicing vs. swiping, on the basis of the syntactic distribution of the pronounced parts of the elliptical clauses. Accordingly, in sluicing, the whitem bears accent because it is syntactically the deepest item that is pronounced. In swiping, on the other hand, the wh-item does not bear nuclear accent because there is another item, i.e. the preposition, that is syntactically deeper than the whitem. We offered a prosodic licensing condition which states that while WTH can bear accent, it cannot bear nuclear accent. Given this condition, in cases in which the $w h$-item bears nuclear accent (both as a result of the default syntactic nuclear accent placement algorithm and as a result of information structure related accent placement), we predicted that the use of WTH yields unacceptability. Given that, unlike in swiping, in sluicing the $w h$-item bears nuclear accent, we predicted that WTH in such a prosodic environment cannot be licensed. We provided additional evidence for our claim from other elliptical clauses and non-elliptical clauses in British English both in information structurally neutral and marked contexts, in which the location of nuclear accent placement may differ. We extended our prosodic licensing account of WTH to a language with similar prosodic typology - the prosodically right prominent Dutch. We have shown that Dutch wh-phrases containing epithets pattern together with British English WTH phrases when it comes to their distribution across elliptical and non-elliptical clauses. We have also shown, with reference to Hungarian, that the prosodic licensing condition we offer for British English and Dutch is not universally applicable to all languages, but is bound to the conditions of language-specific prosodic grammars.

\section{REFERENCES}

Bates, Douglas, Martin Maechler, Ben Bolker \& Steve Walker. 2015. Fitting linear mixed effects models using lme4. Journal of Statistical Software 67.1, 1-48.

Beckman, Mary \& Janet Pierrehumbert. 1986. Intonational structure in English and Japanese. Phonology 3, 255-309.

Boersma, Paul \& David Weenink. 2011. PRAAT: Doing phonetics by computer [computer program]. http://www.praat.org/.

Büring, Daniel. 2016. Intonation and meaning. Oxford: Oxford University Press.

Chung, Sandra. 2006. Sluicing and the lexicon: The point of no return. In Rebecca T. Cover \& Yuni Kim (eds.), Proceedings of 31st Berkeley Linguistics Society (BLS 31), 73-91. Berkeley, CA: Berkeley Linguistics Society.

Cinque, Guglielmo. 1993. A null theory of phrase and compound stress. Linguistic Inquiry 24, 239-297.

Culicover, Peter W. \& Ray Jackendoff. 2005. Simpler syntax. Oxford: Oxford University Press.

Dehé, Nicole. 2014. Parentheticals in spoken English: The syntax-prosody relation (Studies in English Language). Cambridge: Cambridge University Press. 
Den Dikken, Marcel \& Anastasia Giannakidou. 2002. From hell to polarity: Aggressively non-Dlinked wh-phrases as polarity items. Linguistic Inquiry 33, 31-61.

É. Kiss, Katalin. 2002. The syntax of Hungarian. Cambridge: Cambridge University Press.

Embick, David \& Rolf Noyer. 2007. Distributed morphology and the syntax/morphology interface. In Gillian Ramchand \& Charles Reiss (eds.), Oxford handbook of linguistic interfaces, 289-325. Oxford: Oxford University Press.

Féry, Caroline. 2011. German sentence accents and embedded prosodic phrases. Lingua 121, 1906-1922.

Féry, Caroline \& Shinichiro Ishihara. 2010. How focus and givenness shape prosody. In Malte Zimmermann \& Caroline Féry (eds.), Information structure: Theoretical, typological, and experimental perspectives, 36-63. Oxford: Oxford University Press.

Gussenhoven, Carlos. 1984. On the grammar and semantics of sentence accents. Dordrecht: Foris.

Gussenhoven, Carlos. 1994. Focus and sentence accents in English. In Peter Bosch \& Rob van der Sandt (eds.), Focus and natural language processing, vol. III, 83-92. Heidelberg: IBM Deutschland.

Gussenhoven, Carlos. 2005. Transcription of Dutch intonation. In Sun-Ah Jun (ed.), Prosodic typology: The phonology of intonation and phrasing, 118-145. Oxford: Oxford University Press.

Hartman, Jeremy \& Ruixi Ressy Ai. 2009. A focus account of swiping. In Kleanthes Grohmann \& Phoevos Panagiotidis (eds.), Selected papers from the 2006 Cyprus Syntaxfest, 92-122. Newcastle: Cambridge Scholars Publishing.

Hoeksema, Jack \& Donna Jo Napoli. 2008. Just for the hell of it: comparison of two taboo-term constructions. Journal of Linguistics 44, 347-378.

Huang, C.-T. James \& Masao Ochi. 2004. Syntax of the hell: Two types of Dependencies. In Keir Moulton \& Matthew Wolf (eds.), Proceedings of the 34th Annual Meeting of the North Eastern Linguistic Society (NELS 34), 279-293. Amherst, MA: GSLA.

Kahnemuyipour, Arasalan. 2004. The syntax of sentential stress. Ph.D. dissertation, University of Toronto.

Kentner, Gerrit. 2007. Prosodic phrasing in elliptic and non-elliptic coordinations. In Jürgen Trouvain \& William J. Barry (eds.), Proceedings of the 16th International Congress of Phonetic Sciences (ICPhS XVI), 1125-1128. Saarbrücken: Universität des Saarlandes.

Kim, Jeong-Seok. 1997. Syntactic focus movement and ellipsis: A minimalist approach. Ph.D. dissertation, University of Connecticut.

Ladd, D. Robert. 1996. Intonational phonology. Cambridge: Cambridge University Press.

Lakoff, George. 1974. Syntactic amalgams. In Michael Galy, Robert Fox \& Anthony Bruck (eds.), Papers from The Tenth Regional Meeting of the Chicago Linguistics Society (CLS 10), 321-344. Chicago, IL: Chicago Linguistics Society.

Lenth, Russell. 2018. emmeans: Estimated Marginal Means, aka Least-Squares Means. R package version 1.2.4. Retrieved from https:/CRAN.R-project.org/package=emmeans.

Liberman, Mark \& Janet Pierrehumbert. 1984. Intonational invariance under changes in pitch range and length. In Mark Aronoff \& Richard. T. Oehrle (eds.), Language sound structure, 157-233. Cambridge, MA: MIT Press.

Mangiafico, Salvatore. 2018. rcompanion: Functions to Support Extension Education Program Evaluation. R package version 2.0.0. https://CRAN.R-project.org/package=rcompanion.

Merchant, Jason. 2001. The syntax of silence. Oxford: Oxford University Press.

Merchant, Jason. 2002. Swiping in Germanic. In Jan-Wouter Zwart \& Werner Abraham (eds.), Studies in comparative Germanic syntax, 289-315. Amsterdam: John Benjamins.

Mycock, Louise. 2007. Constituent question formation and focus: A new typological perspective. Transactions of the Philological Society 105.2, 192-251.

Nespor, Marina \& Irene Vogel. 1986. Prosodic phonology. Dordrecht: Foris.

Joseph D., O'Connor \& Gorden F. Arnold. 1973. Intonation of colloquial English, 2nd edn. London: Longman.

Ortega-Santos, Iván, Masaya Yoshida \& Chizuru Nakao. 2014. On ellipsis structures involving a whremnant and a non-wh-remnant simultaneously. Lingua 138, 55-85.

Pesetsky, David. 1987. Wh-in-situ: Movement and unselective binding. In Eric Reuland \& Alice ter Meulen (eds.), The representation of (in) definiteness, 98-129. Cambridge, MA: MIT Press.

Radford, Andrew \& Eiichi Iwasaki. 2015. On Swiping in English. Natural Language \& Linguistic Theory 33.2, 703-744.

Richards, Norvin. 2001. Movement in languages: Interactions and architectures. New York: Oxford University Press. 
Rosen, Carol. 1976. Guess what about? In Alan Ford, John Reighard \& Rajendra Singh (eds.), Papers from the 6th Meeting of the North Eastern Linguistic Society (NELS 6), 205-211. Montreal: Montreal Working Papers in Linguistics.

Ross, Haj Robert. 1969. Guess who? In Robert I. Binnick, Alice Davison, Georgia M. Green \& Jerry L. Morgan (eds.), Papers from The Fifth Regional Meeting of the Chicago Linguistics Society (CLS 5), 252-286. Chicago, IL: Chicago Linguistic Society.

Sag, Ivan A. \& Joanna Nykiel. 2011. Remarks on sluicing. In Stefan Müller (ed.), Proceedings of the 18th International Conference on Head-driven Phrase Structure Grammar, 188-208. Stanford, CA: CSLI Publications.

Sprouse, Jon. 2006. The Accent Projection Principle: Why the hell not? Penn Working Papers in Linguistics 12, 349-359.

Szendrői, Kriszta. 2003. A stress-based approach to the syntax of Hungarian focus. The Linguistic Review 20.1, 37-78.

Truckenbrodt, Hubert. 1995. Phonological phrases: Their relation to syntax, focus, and prominence. Ph.D. dissertation, MIT.

Truckenbrodt, Hubert. 1999. On the relation between syntactic phrases and phonological phrases. Linguistic Inquiry 30, 219-255.

Truckenbrodt, Hubert. 2006. Phrasal stress. In Keith Brown (ed.), The encyclopedia of languages and linguistics, vol. 9, 2nd edn. 572-579. Oxford: Elsevier.

Truckenbrodt, Hubert. 2007. Upstep on edge tones and on nuclear accents. In Carlos Gussenhoven \& Tomas Riad (eds.), Tones and tunes: Studies in word and sentence prosody, vol. 2, 349-386. Berlin: Mouton de Gruyter.

Truckenbrodt, Hubert. 2013. An analysis of prosodic F-effects in interrogatives: Prosody, syntax and semantics. Lingua 124, 131-175.

van Craenenbroeck, Jeroen. 2010a. The syntax of ellipsis: Evidence from Dutch dialects. Oxford: Oxford University Press.

van Craenenbroeck, Jeroen. 2010b. Invisible last resort: A note on clefts as the underlying source for sluicing. Lingua 120.7, 1714-1726.

Vicente, Luis. 2018. Sluicing and its subtypes. In Jeroen van Craenenbroeck \& Tanja Temmerman (eds.), The Oxford handbook of ellipsis, 479-503. Oxford: Oxford University Press.

Zubizarreta, Maria Luisa. 1998. Prosody, focus, and word order. Cambridge, MA: MIT Press.

Zubizarreta, Maria Luisa. 2016. Information structure and nuclear stress. In Caroline Féry \& Shinichiro Ishihara (eds.), Encyclopedia on information structure, 165-184. Oxford: Oxford University Press.

Authors' addresses: (Güneş)

Leiden University Centre for Linguistics (LUCL), Leiden University,

P.O. 9515, 23300 RA Leiden, The Netherlands

$\&$

English Department, University of Tübingen,

Englisches Seminar, Philosophische Fakultät, Wilhelmstr. 50 (Brechtbau), 72074 Tübingen, Germany

gunesguliz@gmail.com

(Lipták)

Leiden University Centre for Linguistics (LUCL), Leiden University,

P.O. 9515, 23300 RA Leiden, The Netherlands

A.Liptak@hum.leidenuniv.nl 